\title{
UNA NUEVA APORTACIÓN AL PATRIMONIO HISTÓRICO Y ARTÍSTICO \\ NACIONAL AL AMPARO DE LA REAL ORDEN DE 3 DE MAYO DE 1840: \\ EL INVENTARIO DE SEPULCROS DE LA PROVINCIA DE CÁDIZ *
}

\author{
JUAN RAMÓN CIRICI NARVÁEZ \\ UNIVERSIDAD DE CÁDIZ
}

RESUMEN: A resultas de los efectos que los procesos desamortizadores tuvieron sobre el patrimonio histórico-artístico español durante los gobiernos liberales de la primera mitad del Siglo XIX, una Real Orden de mayo de 1840 tratará de salvaguardar, e inventariar, los sepulcros y panteones considerados de relevancia tanto por la naturaleza de los inhumados, reyes y héroes, como belleza y mérito artístico de los mismos. Es el caso del informe emitido por el Gobierno de la provincia de Cádiz, haciendo testimonio y valoración de los mismos. Sobre ellos hacemos su seguimiento y actualidad, situación y estudio.

PALABRAS CLAVE: Desamortización, Inventario, Panteones y Sepulcros, Provincia de Cádiz.

\section{A NEW CONTRIBUTION TO THE NATIONAL HISTORICAL AND ARTISTIC HERITAGE UNDER THE ROYAL ORDER OF MAY 3, 1840: THE INVENTORY OF SEPULCHRES OF THE PROVINCE OF CÁDIZ}

\begin{abstract}
As a result of the effects that the confiscation processes had on the Spanish historical-artistic heritage during the liberal governments of the first half of the 19th century, a Royal Order of May 1840 will try to safeguard, and inventory, the tombs and pantheons considered of relevance. both because of the nature of the buried, kings and heroes, as well as their beauty and artistic merit. This is the case of the report issued by the Government of the province of Cádiz, making testimony and assessment of them. About them we monitor and update, situation and study.
\end{abstract}

KEYWORDS: Confiscation, Inventory, Pantheons and Sepulchres, Province of Cádiz.

\footnotetext{
* Mi agradecimiento a todas las instituciones y personas que han facilitado, de una u otra forma, el desarrollo de este trabajo: Escuela de Suboficiales de la Armada, San Fernando, Delegación de Cultura, Ayuntamiento de Sanlúcar de Barrameda e IES El Convento, Bornos.
} 
$\mathrm{Al}$ amparo del proceso desamortizador desarrollado en España durante la Regencia de Dña. María Cristina y, posteriormente, del General Baldomero Espartero, años 1833-1844, una Real Orden de 3 de mayo de 1840 “... manda, que se informe á S. M. del estado en que se halle el Panteón del Monasterio de Poblet que contiene los restos de los Reyes de Aragón, y que los Gefes políticos remitan al Ministerio de la Gobernación noticia de los templos de su respectiva provincia en que ecsisten sepulcros que, por serlo de Reyes o personages célebres, ó por la belleza y mérito de su construcción, merezcan conservarse cuidadosamente; entendiéndose lo mismo respecto de cualquier monumento no cinerario que sea digno de mencionarse" ${ }^{1}$.

Sin entrar en el fondo de las circunstancias, ni de las especificas que afectan al Monasterio de Poblet y sus Sepulcros Reales ${ }^{2}$, centramos nuestra atención en la respuesta que a la misma da del Jefe Político de la provincia de Cádiz, tanto por lo que de aportación al conocimiento del patrimonio gaditano presenta como nacional a la postre.

Varias son las consideraciones a tener en cuenta en este documento. Primero, el valor de los inventarios y catálogos históricos y $\operatorname{artísticos}^{3}$; segundo, su contribución al entendimiento del proceso desamortizador, en general, y, en particular, su incidencia en el campo de las artes y la cultura; y, tercero, por lo que de aportación real y concreta tiene a unas obras, que, como la propia Orden califica, se adscriben a importantes personajes, monarquía y célebres -dice-, o por su singular belleza y mérito artístico. Y es de esta tercera opción de la que vamos a hablar.

El citado expediente de contestación a la Real Orden presenta dos escritos ${ }^{4}$, que se sustancian en uno. El primero, de 4 de diciembre de 1840, proviene directamente del Jefe Superior Político de la Provincia de Cádiz, José $\mathrm{M}^{a}$ Riesch. Dirigido al Excmo. Sr. Secretario de Estado y del Despacho de Gobernación de la Península dice así:

\footnotetext{
${ }^{1}$ FERRATER, Estevan de y FERIGLE, Pablo: Recopilación Estractada, Ordenada y Metódica de las Leyes y Reales Disposiciones promulgadas en los años desde el de 1833 al 1841, incluyendo las de la anterior época constitucional que han sido validadas., Tomo III, Barcelona, 1841, pag. 295-6.

2 Tras el definitivo abandono de los monjes en 1835, los saqueos de las tumbas en busca de tesoros habían provocado importantes destrozos en los mausoleos así como la profanación de los restos mortales. El incierto destino de tan notable patrimonio, singular Panteón Real de la Cotrona de Aragón, llevará a las autoridades a su regulación y conocimiento, no, ya, solo del Monasterio catalán sino de cuantos, en similares circunstancias, existieran en el Estado. Ver NAVASCUÉS PALACIO, P.: "Los sepulcros reales de Poblet", Descubrir el Arte, no 19, 2000, ps. 98-101.

${ }^{3}$ Léase MUÑOZ COSME, Alfonso: "Catálogos e inventarios del patrimonio en España”, coord. A. LópezYarto Elizalde, El catálogo monumental de España (1900-1961): investigación, restauración y difusión, 2012, pgs. 13-36.

4 Sección de Arquitectura. Informes. CPHMA/ Sig. 2-46-3. Leg. 5. Archivo Academia Bellas Artes San Fernando Madrid.
} 


\section{"No 229, 4 Sección. Exmo. Señor}

Cumpliendo este Gobierno Político con la Real Orden circular que en 3 de Mayo de este año le fue comunicada por ese Ministerio, para que se remita al mismo una noticia de los Templos en que existan sepulcros que por serlos de Reyes, o personajes célebres, o bien que por la belleza de su construcción merezca conservarse cuidadosamente, atendiéndose lo propio respecto de cualquier otro monumento no cinerario que sea digno de mencionarse; y después de haber reclamado de los respectivos Alcaldes constitucionales de los pueblos de esta provincia de los datos necesarios, tengo la honra de pasar a las superiores manos de V. E. el resultado de los mismos, consignados en la adjunta relación. Dios Guarde a V. E. muchos años. Cádiz 4 de diciembre de 1840".

Y, efectivamente, al oficio se acompaña la "Relación de los Templos de la Provincia de Cádiz en que existan sepulcros que, por serlos de Reyes, o personajes célebres, o que por la belleza y mérito de su construcción merezca conservarse". Por motivos que escapan no se incluye la capital, Cádiz, refiriéndose que "Con respecto a esta capital, se acompaña copia del informe dado por la Academia Gaditana al Alcalde $1^{\circ}$ constitucional".

El segundo escrito se corresponde con una copia posterior, realizada, ya, en Madrid y que, junto al texto primero, incorpora el informe proporcionado por la Academia Gaditana al Alcalde Constitucional de Cádiz, Sr. López Domínguez. En este caso, junto a la prelación de sepulcros, se incorporan otras consideraciones respecto al estado en que se encuentran los templos y conventos suprimidos en la ciudad y provincia, estado, interés y posibles destinos. Firmado el 30 del mismo mes de diciembre de 1840 es copia, como dije, del enviado por el Gobierno Político de la Provincia.

Por su parte, y tomadas en cuenta las consideraciones, Gobernación dará paso del documento a la Academia madrileña de San Fernando para "que informe en su vista lo que crea conveniente puede hacerse con los monumentos cinerarios y Conventos de mérito artístico e histórico que comprenden aquellas. ”Cuatro años después el expediente permanecerá abierto $^{5}$.

Si bien en su extensión no viene, en preciso, al tema no declino por ello la reflexión al anexo así como el remate final cinerario. En primer lugar voy a encender una vela al cuerpo académico de Cádiz. Su informe, no solo repasa los monumentos religiosos desamortizados de valor histórico-artístico de la capital, sino que hace lo propio con los de la provincia, destacando sus calidades y significaciones y haciendo notar su preocupación por sus venturas y utilidades. Así

\footnotetext{
5 Ídem. Nota al margen: "A la Sección le es imposible informar sobre un expediente que está hace cuatro años despachado y que tal vez los monumentos de que se hacen mención habrán desaparecido; la Sección desea que este expediente se una a los nuevos datos que vengan de esta preciosa Provincia y unidos informar por extenso. Madrid 21 de agosto 844 Firman: Carderera y Álvarez. Únase al espediente según desea la Sección.”
} 
del Convento de San Agustín destaca el Altar Mayor y los retablos de los muros laterales, estos últimos "de mármoles y escaida -sic-". Del templo de San Felipe de Neri dice no detenerse por "ser de un mérito demasiado conocido en toda la nación"; del de El Carmen, frente a "una mala portada, la construcción interior del Templo es magnífica por su elevación y altura de la nave principal". De los Conventos de San Francisco y Capuchinos subraya su utilidad pública, el primero, "por la grandiosidad de la Iglesia, los tres espaciosos patios arqueados que contiene y los dilatados salones que los circundan, y, el segundo, para establecimiento que requiera ventilación y limpieza por estar dividida su construcción en dos altos toda de bóvedas". En ambos casos acierta en el diagnóstico dando lugar el franciscano a sendas plazas públicas, Mina y Loreto-San Francisco, y el de los capuchos a hospedería asistencial. Destino similar al templo de los Descalzos del que, si bien "por su posición central, que lo tiene muy concurrido, presentaría inconveniente...el no conservarlo", será derribado dando lugar a nuevos espacios públicos, plaza de las Flores y parque Jiménez Guerra. En el caso de la Catedral nueva, la Academia contrasta la profundidad los cimientos y obra subterránea, por debajo del nivel del mar contiguo, con la altura de su cuerpo principal, por encima de los más altos edificios de la población.

En cuanto a los establecimientos suprimidos de la provincia señala el Convento de Carmelitas de San Fernando, "que dice tener una escalera de un mérito extraordinario por su construcción atrevida"; el de Santo Domingo de Sanlúcar de Barrameda, "obra maestra de arquitectura greco-romana distinguiéndose la bóveda del coro por su construcción plana atrevida"; el de los Gerónimos, en Bornos; el de Almoraima, al que califica como "Cuna de la Religión de los Mercenarios Descalzos"; el Monasterio de la Cartuja de Jerez, el Convento de Ntra. Sra. del Valle, en la actual población de San José del Valle, el de Regla, Chipiona, "que se halla aislado a orillas del mar entre Cádiz y Sevilla y conceptúa utilísimo para establecimiento de Hospital, Lazareto", y el del Cuervo, del que "asegura ser célebre y muy concurrido por sus aguas medicinales". Estos, y otros "conventos que situados en despoblados y entre tierras", considera la Academia que "parecen puestos a propósito para la formación de nuevas poblaciones, hallándose en ellos Iglesia, capacidad para casas Capitulares y Cárcel; agua en abundancia para el vecindario, caminos practicados; y en fin todas las circunstancias que se requieren para las poblaciones nuevas que serían muy útiles en una provincia tan despoblada". Criterios, igualmente, acertados y refrendados por el posterior crecimiento urbano y demográfico de los citados emplazamientos.

Finalmente, y volviendo a la causa que nos ocupa, se "concluye diciendo que en Cádiz no existe más sepulcro notable que el grandioso cenotafio de mármol, sito en la Iglesia del Carmen, erigido a la memoria de D. Federico Grabina, Capitán General de la Armada". 
Y hagamos, pues, repaso del inventario. Sigámosle la pista. Venturas y desventuras. Génesis y actualidad.

-Jerez de la Frontera. Dice el documento:

"En la Iglesia del Monasterio de Cartujos de Santa María de la Defensión se encuentra delante del altar mayor el sepulcro del fundador de dicho Monasterio; cubierto de una hermosa loza de piedra jaspe en la cual está grabada su imagen de cuerpo entero, con morrión, pero sin relieves, escudo de armas a los pies y en actitud de empuñar la espada; alrededor de la citada piedra se lee una inscripción latina que traducida dice: Aquí yace el noble caballero Álvaro Obertos de Valeto, vecino que fue de esta ciudad de Jerez de la Frontera, fundador ydotador de este monasterio de cartuja; falleció año de 1482"6 (Figuras 1).

Figuras 1

\section{Presbiterio y losa sepulcral de D. Álvaro Obertos de Valeto}
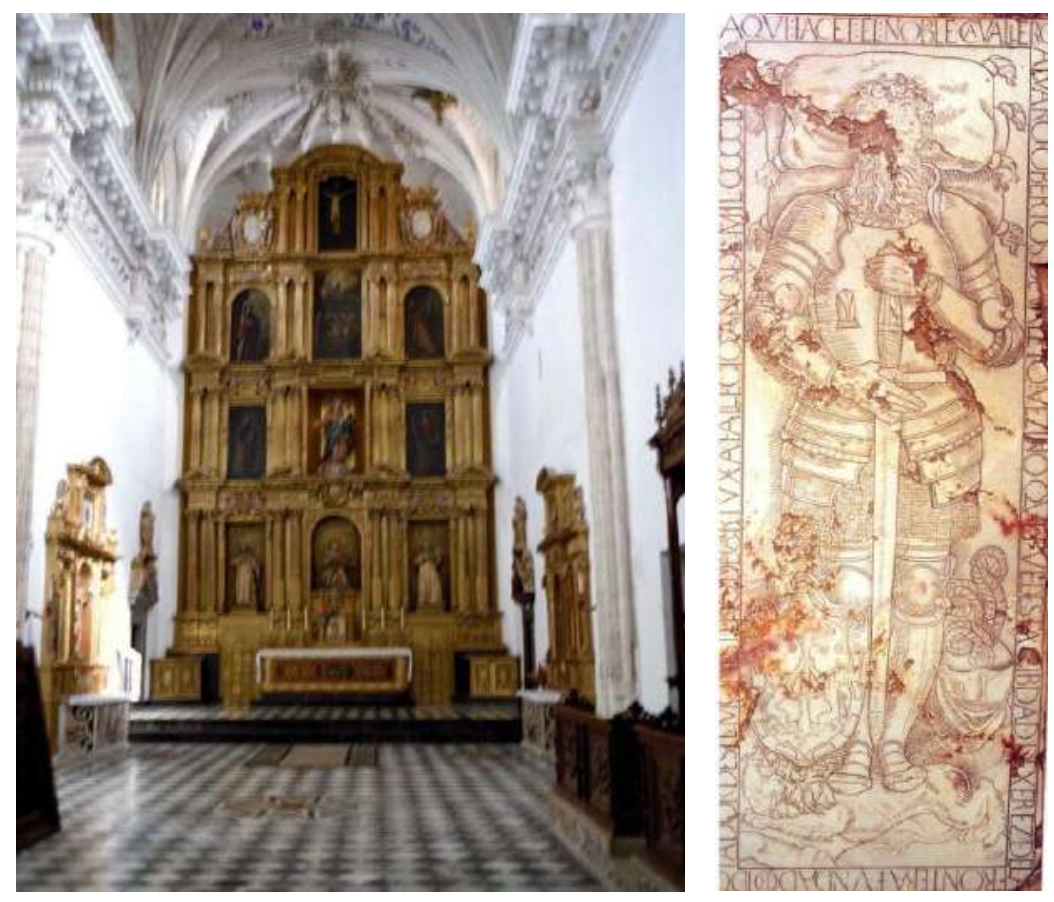

Pese a los numerosos avatares por los que pasó el establecimiento, especialmente a lo largo del siglo XIX, el mausoleo existe en la actualidad, en su original emplazamiento, constituyendo, sin duda, uno de los monumentos funerarios más antiguo de la provincia. Iniciada la fundación bajo el patronazgo del jurado Don Alvaro Obertos de Valeto en 1463, los trabajos de su construcción se prolongarían a lo largo de los siglos siguientes?.

\footnotetext{
${ }^{6}$ Textualmente: AQUI IACE EL NOBLE CAVALLERO ALVARO OBERTOS DE VALETO VEZINO QUE FUE DSTA CIBDAD DE XEREZ DE LA FRONTERA FUNDADOR I DOTADOR DESTE MONASTERIO DE CARTUXA FALLECIO AÑO DE MILCCCCLXXXII.

${ }^{7}$ AROCA VICENTI, Fernando: El Arte en Jerez: Historia de Jerez de la Frontera, vol. 3., Diputación P. de Cádiz, 1999, p. 38.
} 
A destacar la monumental portada principal, levantada en el siglo XVI, por el arquitecto jerezano Andrés de Ribera, dentro de lo que podemos considerar el clasicismo andaluz, a cuya izquierda se encuentra la Cruz de la Defensión, que da nombre al conjunto, y paso al amplio compás que se cierra, al fondo, con la fachada barroca y siglo XVII del templo. El interior, siguiendo el modelo cartujano, se resuelve con una sola nave, dividida en cuatro tramos, y gran arco toral que abre la cabecera de trazado poligonal.

Delante del presbiterio, o Altar Mayor, como reza en el informe, encontramos la lauda sepulcral de Don Álvaro Obertos de Valeto. De mármol blanco, flanqueada por una cenefa, presenta al caballero de cuerpo entero, con armadura y espadón, en las manos y apoyado en el cuerpo. Luce pelo largo y larga barba. A sus pies yace un león tumbado y, a los lados, el yelmo con cimera y el escudo de los Morla: un pino con dos leones rampantes, sobre ondas de plata y azur. Mayorazgo que heredó de su abuela doña Leonor Martínez de Morla. Un cierto deterioro, grietas en la loza, roba lucidez y precisión al relieve.

"En la Iglesia Parroquial de San Miguel, Capilla del Santo Cristo se halla el sepulcro de Don Diego Pavón de Fuentes, caballero del orden de Calatrava y veinte y cuatro de Jerez. Este monumento según la descripción que de él hace el alcalde es magnífico, de tres varas y tercia de largo, y una y dos tercias de ancho, de piedra jaspe encarnada de mucho mérito, labrado con extremada finura, principalmente el escudo de la familia y las dos cruces de Calatrava que tienen a los lados; siendo lo más reparable de esta obra que consta de solas dos piedras" (Figura 2).

\section{Figura 2}

\section{Sepulcro de D. Diego Pavón de Fuentes}

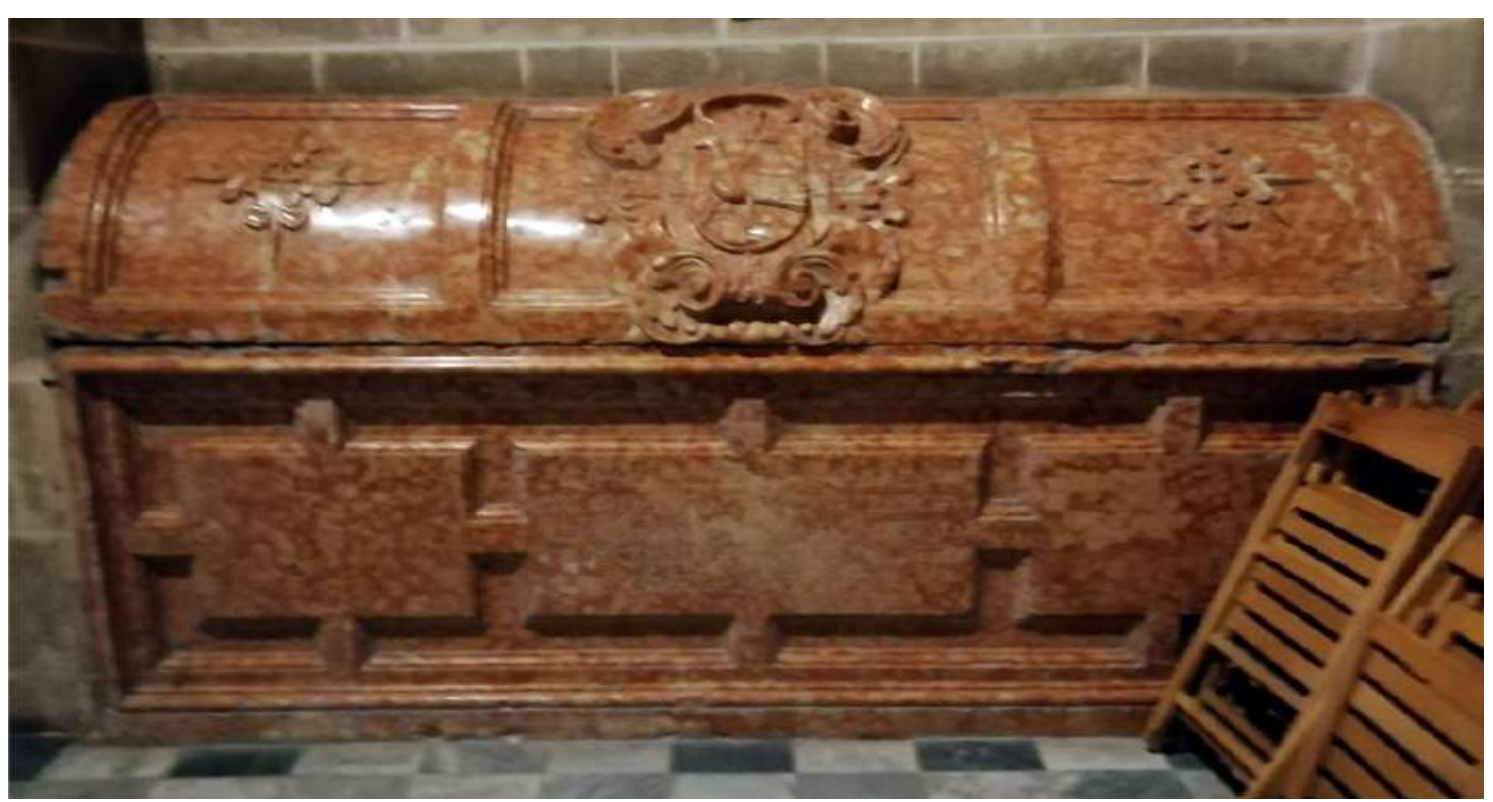


Empieza la dinastía de los Fuentes de Pavón en el alcaide del Alcázar Diego de Fuentes Pavón, veinticuatro de Jerez de la Frontera y regidor de Cádiz, y termina en su quinto descendiente Miguel de Fuentes Pavón y González de Rojas, I marqués de Casa Pavón en 1706, caballero de Santiago, veinticuatro de Jerez de la Frontera y alguacil mayor de la Inquisición. Por la fecha de fallecimiento de la inscripción nos debemos encontrar con el tercero y nieto del fundador.

El templo, auténtica joya del XVI y XVII andaluz, mezcla estilos en una continuada y natural progresión. Iniciados los trabajos en 1480 en un gótico final, hacia 1569 se encontraba ya terminado en sus partes fundamentales. Del exterior destaca su monumental torre-fachada, que incorpora el acceso principal, 1673-1702, así como sendas portadas góticas, laterales, y una tercera que lo hace a la Capilla del Sagrario. En el interior, de planta rectangular con tres naves y crucero, hace lo propio el presbiterio, ochavado y presidido por un magnífico retablo de Martínez Montañés, la Capilla Sacramental, de estilo barroco y comienzo del XVIII y la Sacristía y Antesacristía, renacentistas, 1557 y 1569.

En cuanto a la Capilla de los Pavones pertenece a un incipiente Renacimiento, primera mitad del Siglo XVI, coincidiendo, posiblemente con la dirección de Pedro Fernández de la Zarza, 1537-47, formando un cubo perfecto bajo bóveda de lacería. Así afirma Aroca Vicenti "En el primer cuarto del siglo XVI, aún se estaba cerrando la cabecera del templo junto con las capillas de Santa Ana y del Socorro, la de la familia Pavón incluso, aún se trabajaba en los pilares del crucero y en el de la arcaizante capilla bautismal, conviviendo el gótico tardío con el inicio del Renacimiento"». Dado lo suntuoso del espacio, en uno de los extremos del transepto, la Capilla toma una posición discreta al igual que el retablo barroco que la preside.

En un lateral de la misma, y en mármol rojo, se sitúa el enterramiento del notable Diego Pavón. La potencia de la piedra, de dos bloques, caja y tapa, y la determinación de la labra, escudo e inscripción, otorgan categoría y alto valor artístico a la pieza. "AQUÍ YAZE EL SEÑOR DON DIEGO PAVON DE FUENTES CAVALLERO DE EL ORDEN DE CALATRABA 24 PERPETUO DE ESTA ZIUDAD DE XEREZ DE LA FRONTERA MURIO AÑO DE 1650”, recoge la leyenda del frontis?.

Un Cristo, también barroco y siglo XVII, sobre el catafalco dignifican el lugar.

\footnotetext{
${ }^{8}$ Op. cit., p. 46

${ }^{9}$ Debo de señalar las dificultades presentadas para su acceso y estudio por parte de los responsables del templo.
} 
"En la Capilla de San Pedro de la Iglesia del ex Convento de Franciscos se hallan a los lados del altar dos sepulcros, en cuyas lozas no hay inscripción sino dos figuras de bajorrelieves del tamaño natural, la una de D. Pedro de Zuazo y la otra de su mujer Da María del Espino, Señores de la Isla y Puente de Suazo, quienes enterrados antes en la Iglesia que labraron en la Isleta de Sancti Petri, fueron después trasladados a la expresada Capilla de San Pedro por Juan de Zuazo y Espino, hijo de los antedichos" (Figuras 3).

\section{Figuras 3}

\section{Laudas sepulcrales de D. Pedro de Zuazo y esposa. Detalle de la de $\mathrm{D}^{\mathrm{a}}$ María del \\ Espino}
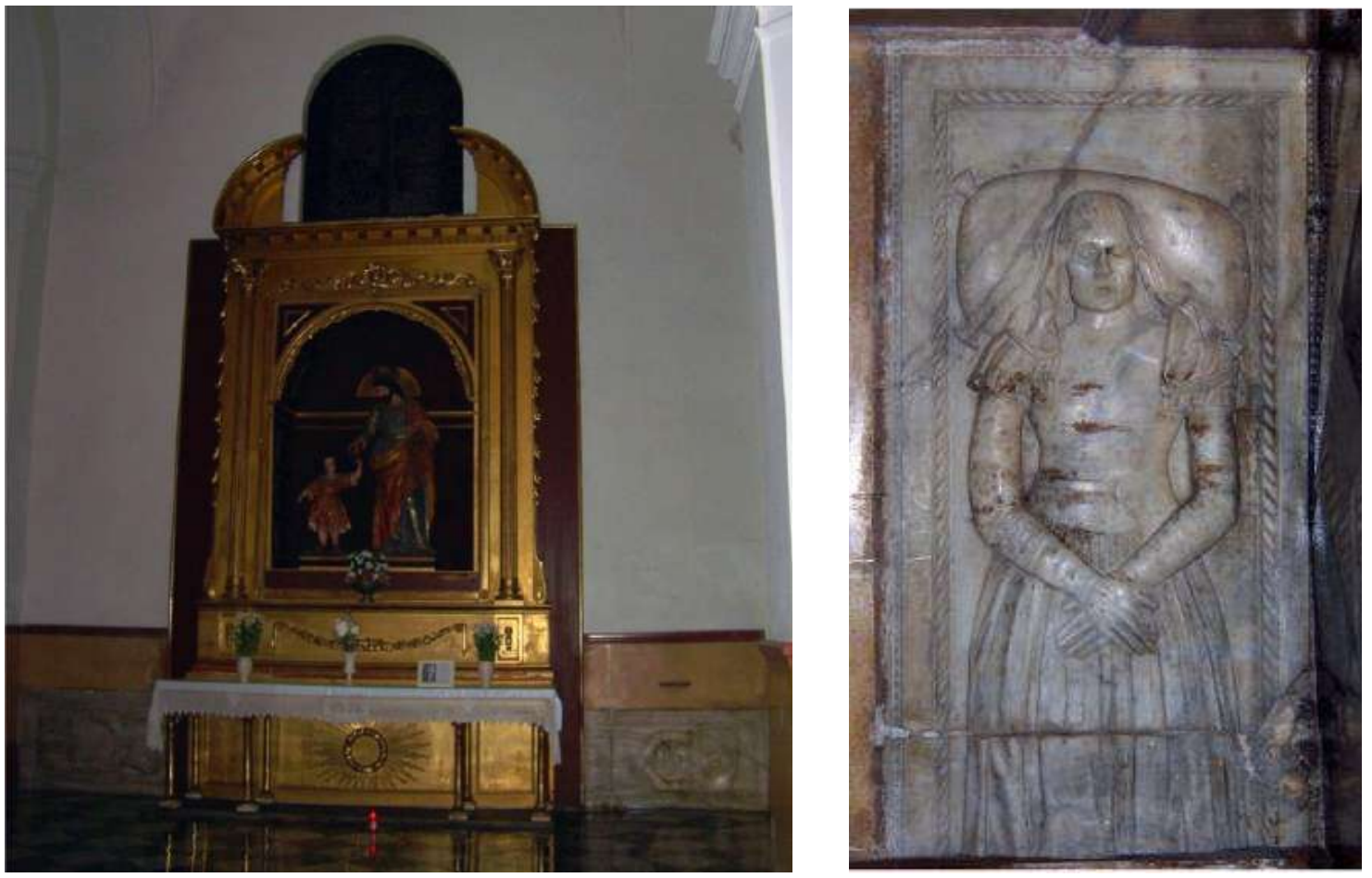

La actual iglesia de San Francisco, situada en pleno centro urbano de Jerez, formaba parte del desaparecido convento de San Francisco, levantado en el extramuros de la ciudad en época medieval. Desamortizado, dando lugar al mercado de abastos y otros espacios públicos y caserío, será definitivamente abandonado por la Orden en fecha reciente.

Reconstruido el templo, entre 1771 y 1787, sobre la base de una anterior fábrica renacentista, presenta planta rectangular con nave central cubierta con bóveda de cañón y lunetos y sendas laterales, divididas en tramos, bajo bóvedas semiesféricas y en las que se abren pequeñas capillas y retablos. Ventanales y una sobria decoración de blancas yesería, ménsulas corintias, con veneras y hojas de acanto, ofrecen un interior armonioso, diáfano y funcional. La portada principal, realizada en piedra, consta de dos cuerpos: el primero formado por columnas pareadas que enmarca el hueco de acceso, y el segundo constituido por una hornacina donde figura la imagen del santo titular. 
De su interior destacamos la Capilla Mayor, bajo bóveda semiesférica rebajada, y arco toral flanqueado por columnas adosadas sobre altos pedestales. Y, junto a ella, en el lado de la Epístola, encontramos la Capilla de San Pedro -o San José-, hoy con un sencillo retablo dieciochesco en cuya hornacina central se encuentra la figura de San José con el niño. A ambos lados de la mesa, sobre el zócalo del muro, se sitúan las laudas, de mármol blanco y en altorrelieve, de los Señores de la Isla y Puente de Suazo, D. Pedro de Zuazo, a la izquierda, y su mujer $D^{a}$ María del Espino, a la derecha del espectador. Pese a no ocupar un lugar destacado su estado de conservación es notable, dejándonos la calidad del trabajo. No hay inscripción y las figuras aparecen de tres cuartos en actitud durmiente y tamaño natural, algo más de metro y medio de longitud. Ciertamente el informe coincide con la realidad.

La noticia de un pleito por la titularidad del Castillo de San Romualdo, en San Fernando y junto al puente Zuazo, entre 1523 y 1533, presentado por Juan F. de Suazo sobre la nulidad del trueque realizado por su abuelo Juan de Suazo con el Marqués de Cádiz, nos sitúa en el tiempo y personajes.

"En la misma Iglesia de San Francisco y delante de una puerta que va desde la sacristía al altar mayor está en el suelo y sin adorno alguno el sepulcro de $\underline{\mathrm{D}^{a} \text { Blanca de }}$ Borbón, mujer del Rey de castilla D. Pedro el Cruel. La loza que lo cubre está partida y sumamente destrozada y falta de letras en su inscripción latina que dice existir allí la expresada Reina de castilla que falleció el año 1361 a los 25 años de edad. Notase en la lápida el empezar con las palabras Christo Optimo Máximo, y el darse a la Reina el apelativo de Diva. A pesar de tan elevado título forzoso es confesar que esta señora fue desgraciada hasta en su sepultura, colocada en un estrecho pasadizo igual con el pavimento del presbiterio y con una inscripción que en breve habrá desaparecido totalmente. Por cuya razón, y atendiendo a lo que ha manifestado el Alcalde de Jerez, sería muy conveniente que el Gobierno dispusiese su traslación a otro lugar más decente de la propia ciudad de Jerez" (Figura 4).

\section{Figura 4}

\section{Piedra del enterramiento de $\mathrm{D}^{\mathrm{a}}$ Blanca de Borbón}

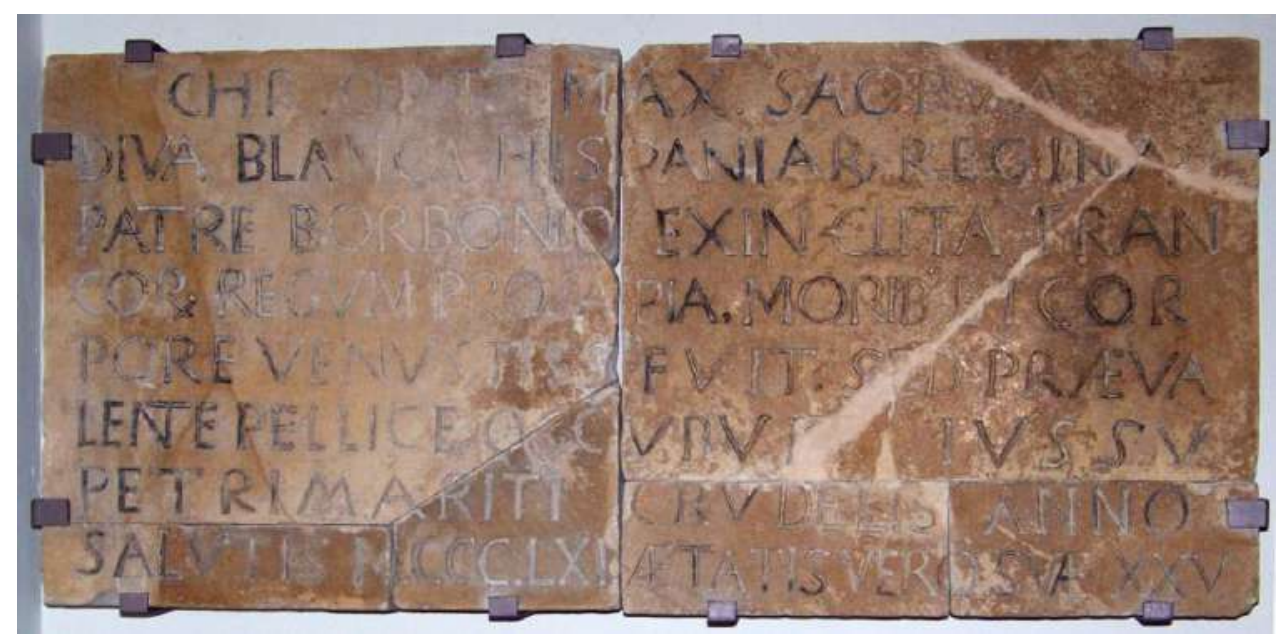


En el presbiterio de esta misma iglesia, pero en el lado del Evangelio, y sobre el testero, se encuentra la loza relativa al enterramiento de Doña Blanca de Borbón, reina consorte de Castilla, y, según la ley canónica, única esposa legítima del rey Pedro I de Castilla. Bien ubicada en el informe, "delante de una puerta que va desde la sacristía al altar mayor está en el suelo y sin adorno alguno", modificaciones posteriores la han llevado al muro y, el cambio de la sacristía al lado contrario, el de la Epístola, a la confusión.

Nada debe de quedar ya de sus restos ni de la sepultura que durante la visita a Jerez de los Reyes Católicos en 1447 ordenaron dar con categoría real.

Asesinada la reina por mandato de su esposo, el cadáver recibió sepultura en una capilla, acaso mayor, de la iglesia del monasterio de San Francisco de Jerez. Será en 1447, cuando a instancias, al parecer, de la reina Isabel la Católica se trasladaron los restos mortales al altar mayor. Pocos datos más hay del real enterramiento, “el sepulcro es de mármol y está adornado con los escudos de Castilla y Borbón"10.

“Cuando se reedificó el templo de San Francisco a finales del siglo XVIII, hay noticias de que los restos de Doña Blanca fueron depositados en una caja de cedro, que se guardó en la celda del prior. Con el advenimiento de la Primera República en 1873, la caja de cedro fue depositada en el Archivo Municipal, para regresar el 24 de febrero del año siguiente al convento de San Francisco, donde se alojó en una pequeña cripta en el lado izquierdo del altar mayor. La última noticia sobre la existencia de la mencionada caja nos la aporta en 1910 el que fuera archivero municipal Adolfo Rodríguez del Rivero, el cual dice que en esa fecha bajó a la cripta junto al entonces alcalde, el marqués de Campo Real, y allí estaba una desvencijada caja con los restos de aquella reina. Dentro de la misma, cuenta, había una lata que contenía un pergamino imposible de tocar pues se deshacía, dado su estado de descomposición" $"$.

En la lauda, discretamente restaurada, pues conserva manifiestamente las huellas del destrozo, puede leerse hoy: "CHR. OPT. MAX. SACRUM. DIVA BLANCA, HISPANIARUM REGINA, PATRE BORBONICO, EX INCLITA FRANCORUM REGUM PROSAPIA, MORIBUS ET CORPORE VENUSTISSIMA FUIT: SED PRAEVALENTE PELLICE, OCCUBUIT JUSSU PETRI MARITI CRUDELI, ANNO SALUTIS 1361, AETATIS VERO SUAE 25." Cuya transcripción viene a decir: Consagrada a Cristo Sumo Bienhechor y Todopoderoso Señor Nuestro, Doña Blanca Reina de las Españas, hija de Borbón descendiente del ínclito linaje de los reyes de Francia, fue

${ }^{10}$ https://es.wikipedia.org/wiki/Blanca_de_Borb\%C3\%B3n. 18/09/2018.
${ }_{11}^{\text {Íbidem. }}$ 
grandemente hermosa de cuerpo y costumbres, mas prevaleciendo la manceba, fue muerta por mandato del rey D. Pedro I el Cruel su marido. Año de Salud de 1361. Siendo ella de 25 años de edad.

Poco más, o nada, se puede añadir.

-San Fernando. Dice el informe:

"En esta ciudad solo existen dos monumentos cinerarios; el uno que contiene los restos mortales de Don José Navarro, Marqués de la Victoria y Capitán General de la Armada y el otro de Don Luis de Córdova, también Capitán General de la Armada” (Figuras 5 y 6).

Tanto D. José Navarro como D. Luis de Córdova, como acontecerá luego a D. Federico Gravina, serán enterrados en primera instancia en distintos emplazamientos, donde se encontrarían en el momento de redacción del informe, para pasar luego por diversas vicisitudes y terminar en el actual Panteón de Marinos Ilustres -P. M. I.- de la propia localidad de San Fernando ${ }^{12}$.

Comenzadas las obras del establecimiento, inicialmente destinado a Iglesia de la Purísima Concepción para la Población Militar de San Carlos, en 1786 a indicación del Rey Carlos III, diseño de Francisco Sabatini y dirección, primero, de Ignacio Imperial Digueri, y, posteriormente, de Gaspar de Molina, Marqués de Ureña, no serán culminadas hasta bien entrado el siglo XX. Será, precisamente, Luis de Córdova y Córdova, a la sazón Capitán General del Departamento, quien coloque la primera piedra.

La falta de fondos y otras contrariedades paralizarán los trabajos a comienzos del nuevo siglo, coincidiendo con la derrota de Trafalgar en 1805. Tras la apertura del Colegio Naval, colindante al mismo en 1845, una Real Orden de 10 de octubre de 1850 estableció asignar el edificio como Panteón para, a su vez, servir de referente de vida a los alumnos que allí cursaban sus estudios. Sólo unos días antes de la inauguración el 17 de noviembre de 1854, onomástica de la Reina, se habían concluidos los sepulcros de Jorge Juan Santacilia, Juan José Navarro, Federico Gravina, Luis de Córdova y Córdova, Ignacio María de Álava, Cayetano Valdés y José Rodríguez de Arias. Finalmente, y entre 1943 y 1959, se cerrará totalmente la cubierta, cúpulas y bóvedas, otorgando su actual presencia.

La disparidad de fechas que encontramos en estos enterramientos se debe a que el gobierno de la Gloriosa Revolución, septiembre de 1868, dispone el traslado de los mismos al Panteón Nacional de Hombres Ilustres, recién inaugurado en el templo de San Francisco

12 https://es.wikipedia.org/wiki/Pante\%C3\%B3n_de_Marinos_Ilustres. 18/09/2018. 
el Grande de Madrid. Una nueva revisión, y con el motivo de la reapertura del Colegio Naval en 1870, dispuso el regreso de los marinos ilustres al Panteón isleño. Regreso que se hará gradualmente.

Don Juan José de Navarro de Viana y Búfalo, nacido en Mesina, Sicilia, en 1687 y muerto en la Isla de León -San Fernando-, en $1772^{13}$, fue un marino y militar español, autor de numerosos tratados para la navegación y el combate naval, destacando, especialmente, su Código de Señales, publicado en Cádiz en 1765, I Marqués de la Victoria, Vizconde de Viana y primer Capitán General de la Real Armada Española.

Participó en la Guerra de Sucesión a las órdenes de Felipe V, ingresando en la Real Armada española en 1717 donde pronto se revelará como instructor de las enseñanzas de matemáticas así como de la "teoría y práctica de la maniobra". Distintos ascensos le llevarán al empleo de Capitán de Navío, 1729, al mando de diferentes buques, tomando parte en la expedición a Orán, 1732, y en la guerra con Inglaterra, 1739, en cuya batalla del Cabo Sicié, -frente a Tolón- resultará herido, siendo reconocido por el rey que le promocionará al cargo de Teniente General, otorgándole, a su vez, el título de Marqués de la Victoria.

Sus numerosos estudios sobre la navegación moderna le permitirán ingresar en 1740 en la Real Academia Española, nombrándole en 1759 el Rey Carlos III Capitán General de la Armada. En estos menesteres, a la edad de 84 años, y en su casa de la Isla, le encontrará la muerte el 5 de febrero de 1772. Vargas Ponce ${ }^{14}$, relata así el fatal desenlace "El 25 del anterior diciembre le acometió un vértigo al curarle un pie de que adolecía: recobrado firmó su correo; mas sobrevenida allí una erisipela, y malinándose la enfermedad, y declarada la gangrena, el 5 de febrero acabó don Juan Josef Navarro su larga y bien empleada vida...”.

Más adelante nos da noticias de las exequias y enterramiento: "No hallándosele ni el numerario suficiente para arreglar la habitación en que debía exponerse su cuerpo, hubo de suplir mil pesos el intendente de Marina, que mandó el rey no se cargasen al asiento del difunto. Y con toda la solemnidad que previene la ordenanza, y con un verdadero pésame que ella no puede prevenir, se dio sepultura al marqués de la Victoria en el convento del Carmen de la Isla. Vimos esta pompa fúnebre, y el todavía venerable cadáver, y oímos algo de lo que dexamos referido en la oración fúnebre, que poco después predicó en sus honras el célebre magistral de Cádiz don Josef Martin y Guzmán”.

Y continúa: "Un año después estuvo á la vista de muchos profesores su incorrupto cuerpo, que no fue embalsamado; todos testificaron no sin sorpresa su conservación, á pesar de la dolencia de que finara. Con nueva solemnidad y nuevo panegírico se hizo la translación

${ }^{13}$ https://es.wikipedia.org/wiki/Juan_Jos\%CC3\%A9_Navarro. 18/09/2018

${ }^{14}$ Vida de Don Juan Josef Navarro, primer Marqués de la Victoria, p.358-360 
al monumento de mármol, que el amor, gratitud y memoria de los marinos erigió á su ilustre gefe, y al que decora un cumplido epitafio, que colocamos entre los apéndices, para extender el buen gusto y la tierna amistad de otro sabio octogenario (don Josef Carbonell) que lloroso se lo consagró”.

El templo en cuestión pertenece al Convento de los Carmelitas Descalzos ${ }^{15}$ cuyas obras se iniciaron en el primer tercio del siglo XVIII, siendo el encargado de las mismas el maestro Juan de San Román. Presenta planta de cruz latina con tres naves, divididas en cinco tramos mediante de pilares, sendas tribunas al crucero y coro alto a los pies. La cubierta se proyecta sobre bóveda de cañón decorada con lunetos en la nave central, bóvedas de aristas en las laterales y cúpula semiesférica en el crucero. Junto a éste, destaca la capilla de Ntra. Sra. del Carmen, poligonal y antigua del Sagrario. El exterior ofrece dos tramos, alto con torreespadaña y frontón triangular, y bajo, dividido en tres calles mediante potentes pilastras toscanas, y donde se abren huecos, ventanas y destacado acceso principal presidido por una hornacina con la imagen de Nuestra Sra. del Carmen.

\section{Figuras 5}

\section{Sepulcro y urna y escudo de armas de D. Juan J. Navarro}
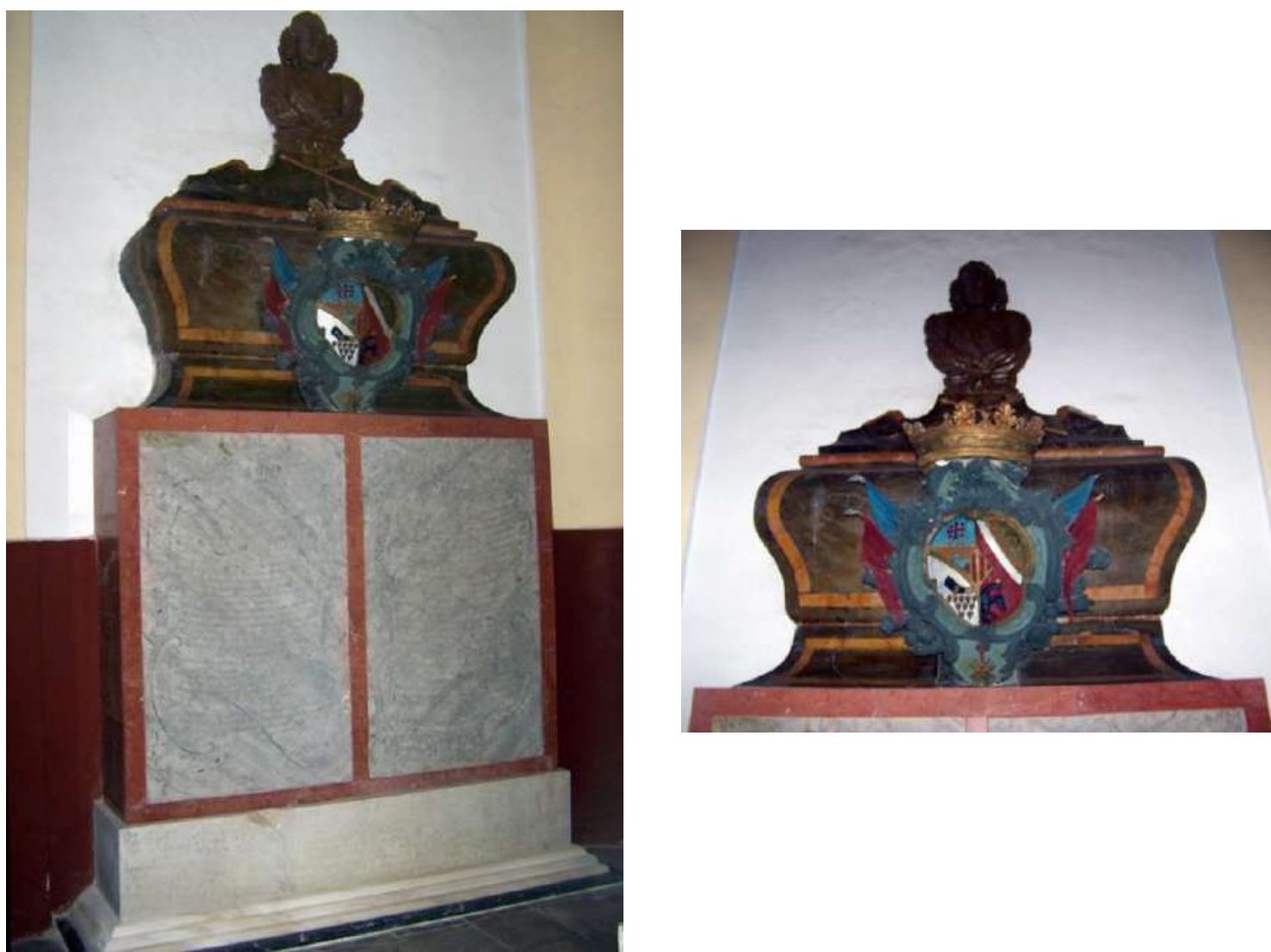

${ }^{15}$ LÓPEZ GARRIDO, L., MARTÍNEZ MONTIEL F. y RAMÍREZ MALO, F.: Guía histórico-artística de San Fernando, San Fernando, 1989 p. 96-100. 
La casa aún conserva estancias fundacionales como "la sala de profundis con sus columnas toscanas que la dividen transversalmente y las yeserías de las escaleras de acceso a ella”. Sin duda la escalera a la que aluden en el informe académico.

Nada queda en la Iglesia del Carmen de San Fernando, y poco más sabemos, del referido mausoleo, el lugar, la fecha, 1773, y que era de mármol. Acaso sería el mismo que luego, en 1854, o mejor 1870, se erigió en el Panteón de Marinos. En cualquier caso sigo en el rastreo del "cumplido epitafio", producto de "...la tierna amistad de otro sabio octogenario (don Josef Carbonell) que lloroso se lo consagró".

Sí encontramos su catafalco en el P. M. I., en el testero de la epístola, junto al Altar Mayor. Tres inscripciones, de difícil lectura, una en el zócalo de la base y sendas enmarcadas por cesuras, a manera de rocalla, y curvo recorrido en el frontis del pedestal glosan la vida del marino. Mayor atención ofrece la urna, también de ondulantes formas y de contrastados mármoles y jaspes, destacando el escudo nobiliario, de llamativa policromía, y la esfinge busto- que se eleva en la tapa.

El segundo sepulcro de la lista se refiere, también, a un ilustre marino: D. Luis de Córdova y Córdova, nacido en Sevilla en 1706 y fallecido en San Fernando, Cádiz, en 1796. En este orden, sucederá a Navarro convirtiéndose en el segundo Capitán General de la Real Armada Española ${ }^{16}$.

Ingresó como guardiamarina en la compañía del departamento de Cádiz, en 1721, ascendiendo rápidamente y ganando el aprecio de superiores y el propio rey Felipe V. En 1732 participó de la toma de Orán y dos años más tarde en la reconquista de Nápoles y Sicilia. En 1747 ascendió Capitán de Navío recibiendo de Fernando VI la encomienda de la Orden de Calatrava.

Hizo escolta a los convoyes de la Carrera de Indias y combatió el contrabando en Cartagena de Indias. En 1779 fue nombrado comandante de la escuadra aliada con Francia y en guerra con Inglaterra, cruzando el Canal de la Mancha con la intención de invadir las Islas Británicas. En 1782 intervino en el bloqueo y toma de Gibraltar. Servicios por los que el Rey le nombrara Director General de la Armada, 1783, y poco después Capitán General

Ya en la Isla de León (San Fernando), fallecerá en julio de 1796, a los 90 años de edad, siendo enterrado en la Iglesia de San Francisco de dicha localidad, a la sazón parroquia castrense. En 1851 se decretará el traslado de sus restos al Panteón de Marinos Ilustres, lo que tuvo definitivo cumplimiento en 1870.

${ }^{16}$ https://es.wikipedia.org/wiki/Luis_de_C\%C3\%B3rdova_y_C\%C3\%B3rdova. 18/09/2018 
La Iglesia de San Francisco ${ }^{17}$ se ubica en los antiguos terrenos del Hospicio de los Franciscanos. El traslado del Departamento de Marina a la Isla de León y las necesidades de la Armada de tener una parroquia propia dio paso a la construcción del templo en el último tercio del siglo XVIII. Este carácter castrense impidió que las leyes desamortizadoras se aplicasen sobre el establecimiento, a la vez, también, conventual.

La iglesia, tras el hall de entrada, presenta planta de cruz latina con tres naves, la central con bóveda de cañón y las laterales de menor altura, y crucero bajo cúpula sobre pechinas. Pilares, con pilastras toscanas, y volada cornisa rompen la uniformidad de su diseño. El exterior, de igual sobriedad y clasicismo, muestra un solo cuerpo con puerta de acceso flanqueada, asimismo, por pilastras y bajo frontón circular sobre el que se eleva una espadaña.

Obras de la época fundacional, y decimonónicas, esculturas, sendas Inmaculadas y un Cristo de la Expiración, y pinturas, Muñoz de la Vega, Carreño de Miranda, al parecer, y Mariano Salvador Maella, enriquecen sus muros y hornacinas.

Pero, al igual que sucedía en la Iglesia del Carmen, nada nos conduce al pensamiento del sarcófago del Capitán General, que otra cosa, que el existente en el P. M. I.. Sobre un doble cubo, de arranque de mármol negro, a manera de zócalo, y bloque blanco, que hace las veces de pedestal, y en cuyo frente se recoge una placa de bronce inscrita, se sitúa la urna funeraria, cuadrada, con un pronunciado escudo de armas, también de mármol blanco, y tapa con remate en forma de vaso cinerario, de jaspe negro, elíptico y acabado en llamas.

\section{Figuras 6}

\section{Urna funeraria y placa de bronce del sepulcro de D. Luis de Córdova}
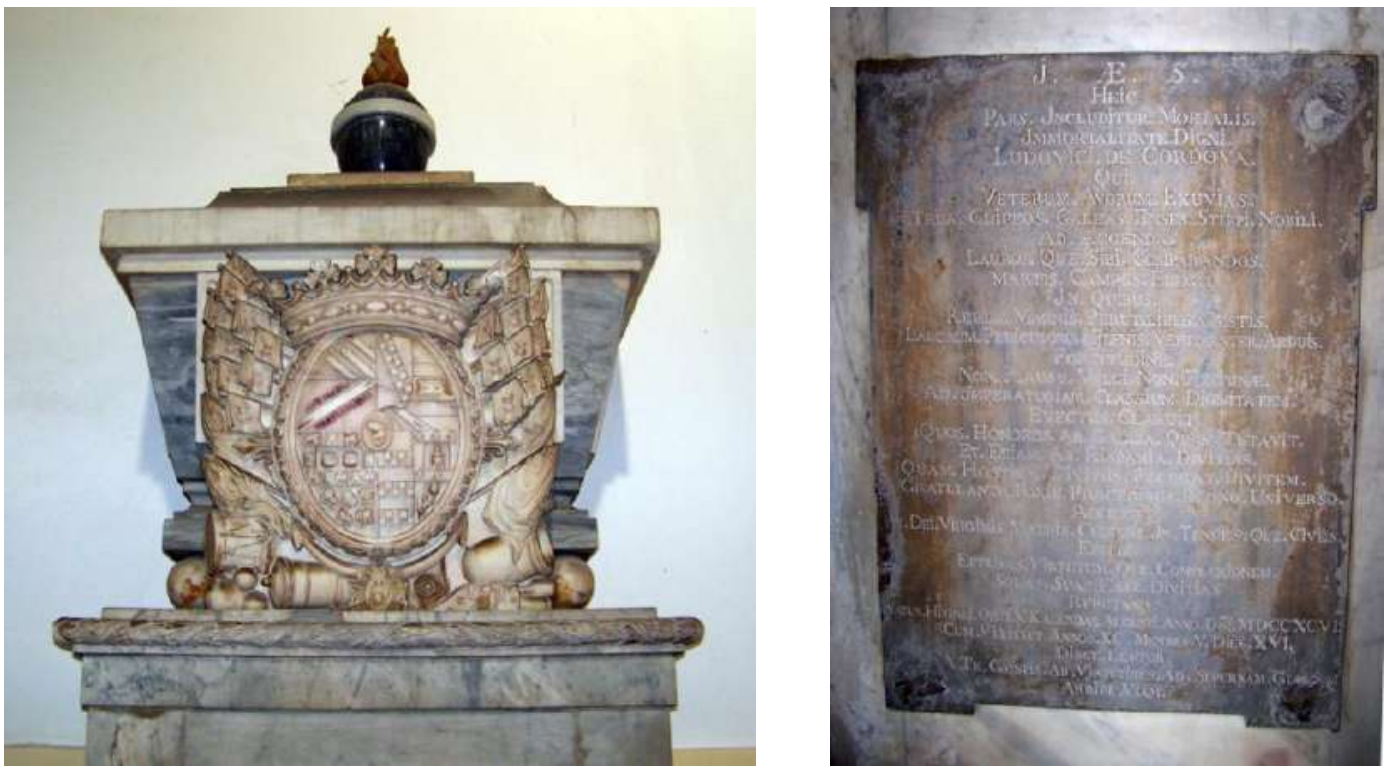

${ }^{17}$ LÓPEZ GARRIDO, L. et al: op. cit., p. 75-79. 
La inscripción, traducida del latín, dice: "AQUÍ ESTA ENTERRADA LA PARTE MORTAL DEL DIGNO DE INMORTALIDAD LUIS DE CÓRDOVA, QUIEN, A FIN DE MULTIPLICAR PARA SUS DESCENDIENTES LOS TROFEOS DE SUS ANTEPASADOS, LANZAS Y ESCUDOS, YELMO Y ESPADAS, Y CONQUISTAR LAUROS PARA SI MISMO, ABRAZO LA PROFESION DE LAS ARMAS, EN LA QUE BRILLO, NO POR HALAGO DEL VULGO NI DE LA FORTUNA, SINO POR SU FORTALEZA, ELEVADO AL EJERCICIO DEL MANDO SUPREMO DE LA ARMADA, DESPUÉS DE LLEVAR A CABO TAN MEMORABLES Y UTILES GESTAS COMO ARDUAS Y PELIGROSAS SOBRE TODA PONDERACION. CUANTOS HONORES RECIBIO DE FRANCIA, A LA QUE DEFENDIO, Y CUANTAS RIQUEZAS OBTUVO DE ESPAÑA, A LA QUE TANTAS PROPORCIONO CON LAS DE SUS ENEMIGOS; APLAUDIDO POR EL REY, LOS NOBLES Y EL REINO ENTERO, TODO LO EMPLEO EN HONOR DE LA VIRGEN MADRE Y EN SOCORRO DE LOS DESGRACIADOS, ENTENDIENDO QUE SOLO LAS ASI EMPLEADAS, JUSTAMENTE CON EL CORTEJO DE LAS VIRTUDES, ERAN SUS VERDADERAS RIQUEZAS. NACIDO EN SEVILLA, MURIO EL 27 DE JULIO DEL AÑO DEL SEÑOR 1796, HABIENDO VIVIDO NOVENTA AÑOS, CINCO MESES Y DIEZ Y SEIS DIAS. APRENDE LECTOR.

EN TODOS TUS NEGOCIOS TOMA SIEMPRE EL CAMINO QUE VA DESDE LAS VIRTUDES A LA GLORIA ETERNA”. Amén, digo yo.

-Sanlúcar de Barrameda. De la ciudad de la manzanilla se recoge:

"En la Iglesia de Carmelitas descalzos se halla depositado el cadáver de D. Diego de Riquelme, Obispo de Plasencia y Presidente que fue del Consejo de Castilla".

Efectivamente, en el Convento de Santa Teresa, de la Orden de las Carmelitas Descalzas, en Sanlúcar de Barrameda, se encuentra el enterramiento de D. Diego Riquelme de Quirós, bajo cuyo patrocinio fue construido entre los años de 1669 y $1675^{18}$. En uso por

\footnotetext{
${ }^{18}$ Hay una interesante bibliografía sobre el establecimiento: CABALLERO OLIVER, Juan Diego: "Conventos femeninos de clausura en Sanlúcar. Convento de las Descalzas", Revista Sanlúcar de Barrameda, n 27, Ed. Santa Teresa, Sanlúcar de Barrameda, 1991; OSLÉ MUÑOZ, Julián: El convento de las Descalzas, Ed. Asociación Sanluqueña de Encuentros con la Historia y el Arte (ASEHA), Sanlúcar de Barrameda, 1996; VELÁZQUEZGAZTELU, Juan Pedro: Fundaciones de todas las iglesias, conventos y ermitas de la Muy Noble y Muy Leal Ciudad de Sanlúcar de Barrameda., Año de 1758 (Manuscrito en paradero desconocido, trascripción manuscrita de Manuel López de Piedra, (¿año?). Estudio preliminar y trascripción de Manuel Romero Tallafigo; dibujos de Cristóbal Mancha Liñán. Asociación Sanluqueña de Encuentros con la Historia y el Arte (ASEHA), Sanlúcar de Barrameda (Cádiz), 1995, p. 475-482; y GARRIDO NEVA, Rocío: "Una alternativa al mecenazgo ducal, el
} 
la comunidad carmelita, que vive la clausura y permite la visita guiada, no ha sido posible obtener fotografía alguna.

El establecimiento, en buen estado de conservación, si bien, al parecer, próximo a su cierre, forma un rectángulo, entre las calles de las Descalzas, en su frente, y Pozo Amarguillo, en su trasera, al que se acogen las dependencias conventuales, en torno a tres patios, e Iglesia. Del exterior destaca la portada del templo, de dos cuerpos, acceso, bajo arco de medio punto y entre pilastras, segundo, con huecos y hornacina, y remate superior en espadaña.

Más información acerca de la sepultura la encontramos en Cadizpedia "Dentro, entre el coro bajo y la tribuna alta para el noviciado, se encuentra la tumba de Don Diego Riquelme de Quirós (1608-1664), obispo sanluqueño que ocupó el cargo de Presidente del Real Consejo de Castilla, nombrado por Felipe IV, y que era el segundo cargo más importante de España, después del propio Rey"19.

"Junto a este enterramiento existen dos criptas en el templo. Una, bajo el altar mayor, destinada a personajes civiles y en desuso, y una segunda, en el subsuelo del coro bajo, en activo y destinada a las monjas de la comunidad"20.

Igualmente son destacables las series de retablos, mayor, de Peter Relingh, y laterales, de estilo rococó, obra del jerezano Andrés Benítez y Perea en 1760.

En sus interesantes Archivo y Biblioteca se pueden encontrar manuscritos de San Juan de la Cruz, Cántico Espiritual-Primera Redacción, Códice A- denominado Códice de Barrameda firmado, corregido y con anotaciones, y carta autógrafa de Santa Teresa.

D. Diego Riquelme de Quirós ${ }^{21}$, nació en Sanlúcar de Barrameda, Cádiz, en 1620, y falleció en Madrid en 1668. Siendo canónigo magistral de la Iglesia Catedral de Murcia, será designado obispo de Ciudad Rodrigo en 1658, permaneciendo en el cargo hasta comienzos del año de 1662, para pasar a la diócesis de Oviedo y, de allí al obispado de Plasencia, 1665, donde continuará hasta el año 1668, en que ocupará la presidencia del Consejo de Castilla y fallecerá unos meses después. Dada su vinculación con Sanlúcar, seis años más tarde, en 1674, su cadáver será trasladado a su ciudad natal y enterrado en el Convento de las Carmelitas Descalzas.

convento de Santa Teresa de Sanlúcar de Barrameda (Descalzas)”, en F. Cruz Isidoro (coord. y ed.), Sanlúcar Señorial y Atlántica. III y IV Jornadas de Investigación del Patrimonio Histórico-Artístico 2013-2014, Sanlúcar de Barrameda, Ayuntamiento de Sanlúcar de Barrameda, pp. 205-242.

19 https://cadizpedia.wikanda.es/wiki/Convento_de_las_Carmelitas_Descalzas_(Sanl\%C3\%BAcar_de_Barra meda). 25/4/2016.

${ }^{20}$ Ibídem.

${ }^{21}$ VELÁZQUEZ-GAZTELU, Juan Pedro: Catalogo de todas las personas ilustres y notables de esta ciudad de Sanlúcar de Barrameda. Desde la mayor antigïedad que se ha podido encontrar en lo escrito, hasta este año de 1760, (Estudio preliminar, transcripción y edición del manuscrito por Fernando Cruz Isidoro), 1995, p. 425. 
Y prosigue en la localidad:

"En el Convento de la Merced, los cadáveres de los Duques de Medina Sidonia D. Manuel Alonso Pérez de Guzmán el Bueno y su esposa Da Juana de Sandoval” (Figuras 7).

\section{Figuras 7}

Cripta y enterramientos de los Duques de Medina Sidonia, D. Manuel -izquierda- y $D^{a}$ Juana -derecha-
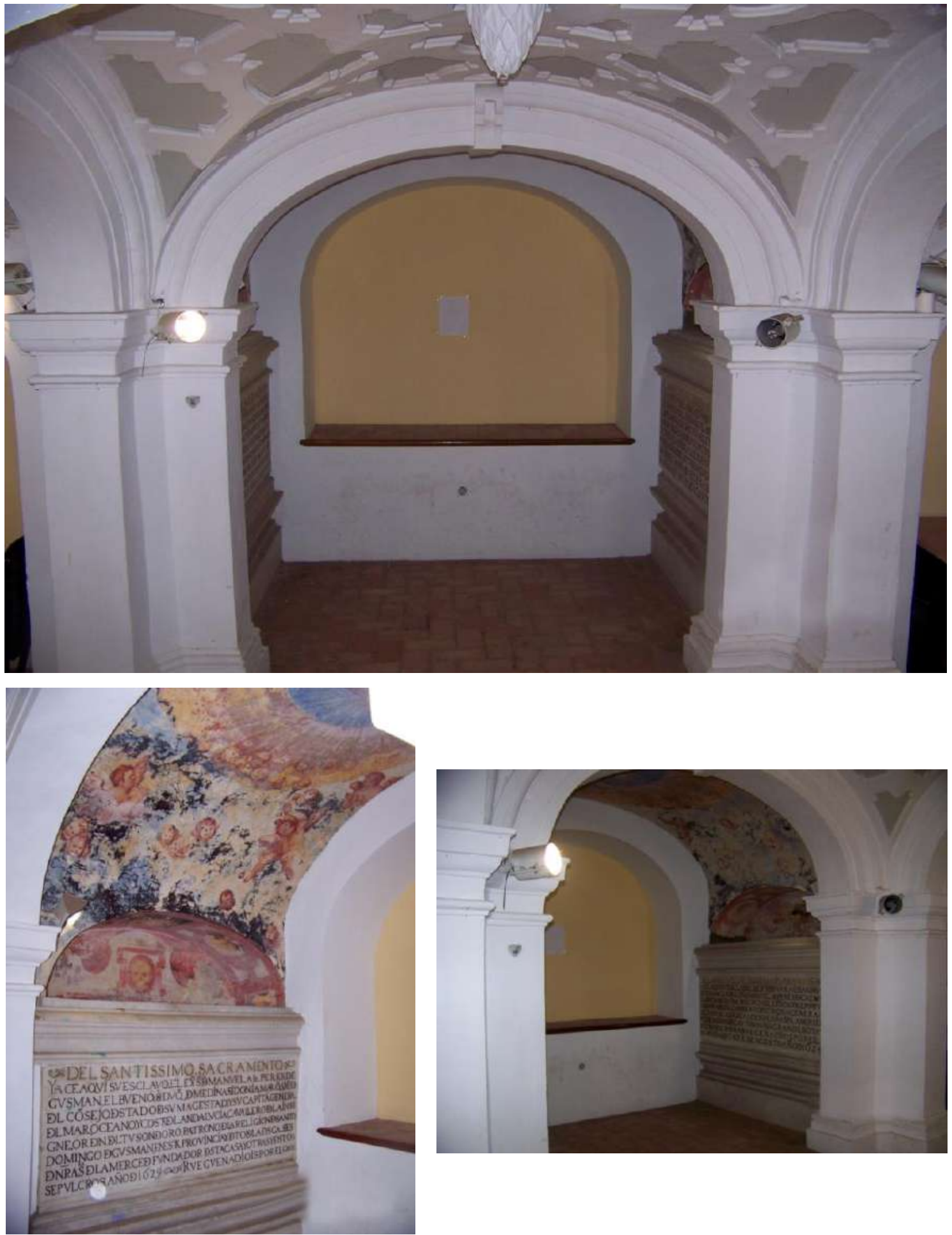
En el Convento de la Merced, en Sanlúcar, hoy convertido en establecimiento cultural multiuso dependiente del Ayuntamiento, en la cripta bajo el presbiterio se encuentran los enterramientos de los Duques de Medina Sidonia D. Manuel Alonso Pérez de Guzmán el Bueno y su esposa $\mathrm{D}^{\mathrm{a}}$ Juana de Sandoval. El establecimiento mercedario ${ }^{22}$ será construido entre los años 1616 y 1625, bajo trazas de Alonso de Vandelvira, con intervención en los diseños de Juan de Oviedo, y el patronazgo de los VIII Duques de Medina-Sidonia, antes citados y allí depositados.

Del conjunto conventual destaca la iglesia, de planta basilical, con tres naves, divididas en cuatro tramos, y crucero con presbiterio plano. La central presenta bóveda de cañón con arcos fajones y decoración de casetones que se proyectan en el tambor y cúpula del crucero. Sobre las naves laterales se abren tribunas balconadas y coro situado a los pies.

La fachada, a manera de retablo, levanta tres cuerpos divididos en tres calles, la central con un pórtico de acceso abierto y tres huecos sobre columnas y resto, bajo y pisos superiores con hornacinas, pilastras y frontones. El resto se decora con huecos y hornacinas de frontones rectos y curvos coronados por un cornisamento motivado de gran efecto decorativo. En el lado de la epístola se alza una torre, cuadrada, con el cuerpo de campanas, y acabada en chapitel revestido de azulejos.

"Bajo el crucero y el altar mayor, excavada en la propia roca ferruginosa virgen, se halla la cripta panteón de los Patronos Fundadores, cubierta por bóvedas de cañón decoradas con yeserías de cartones recortados y planta de tipo cruciforme" ${ }^{23}$.

Siguiendo al profesor Alfredo Morales "Las labores propiamente constructivas quedarían definitivamente concluidas en enero de 1620, siendo una de las últimas... el remate de la media naranja y linterna del crucero. Despues se procedería a terminar la decoracion del templo y se encargarian las piezas del ajuar del mismo... Con igual fecha se encargan diversas cantidades de madera para los bancos y se concluye la cripta para los enterramientos, que fue decorada en su bóveda con un gran escudo de los Guzmán realizado por el escultor Salvador Rodríguez" ${ }^{24}$.

Tras bajar unas escaleras situadas en el testero del evangelio del Altar Mayor, damos con una sala rectangular, a cuya derecha se abre, propiamente, la cripta, de planta cruciforme, bajo arcos y bóvedas de cañón rebajados y prolijamente decorada con molduras y yeserías.

22 MORALES, Alfredo J.: "Alonso de Vandelvira y Juan de Oviedo en la iglesia de la Merced de Sanlúcar de Barrameda", Boletín del Seminario de Estudios de Arte y Arqueología, 1981, págs. 307-320. Ver también CRUZ ISIDORO, Fernando: Alonso de Vandelvira (1544-ca.1626/7). Tratadista y Arquitecto Andaluz, Sevilla, Secretariado de Publicaciones de la Universidad de Sevilla, 2001, pp. 211-237.

${ }^{23} \mathrm{http}: / /$ www.iaph.es/patrimonio-inmueble-andalucia/resumen.do?id=i1226

24 Op. cit., p. 311. 
En el brazo frontal se abren tres huecos, a manera de altar el del centro y acogiendo los catafalcos los laterales. Ambos presentan igual disposición, de mármol blanco, embutido en el muro bajo un pequeño arco e inscripción en su cara externa. En el de la izquierda se puede leer: "DEL SANTISSIMO SACRAMENTO. YACE AQUÍ SU ESCLAVO. EL EXmo Sor Don MANUEL. ALo. PERES. DE GUSMÁN. EL BUENO. $8^{\circ}$ DUQ. De MEDINA SIDONIA MARQUeS. I CONDE DeL CONSEJO DeSTADO De SU MAGESTAD. Y SU CAPITAn GENERAL DeL MAR. OCEANO. Y COSTa DeLANDALUCIA. CAVALLERO De LA INSIGNE. ORDEN DeL TUSON De ORO. PATRONO. De LA RELIGION De SANTO DOMINGO De GUSMAN EN ESTA PROVINCIA. Y De TODA LA DeSCALSES De NTRA Sra De LA MERCED. FUNDADOR De STA CASA Y OTRAS Y DeSTOS SEPULCROS. AÑO De 1629. RUEGUEN A DIOIS POR EL.”

En el de la derecha: "DE LA MADRE DE DIOS MARIA SANTISIMA. YACE AQUÍ SU ESCLABA LA EXma Sa Da JUANA De SANDoBAL I ZERDA MGER DeL EXmo Sor D MANUEL ALO. PERES. De GUZMÁN EL BUENO $8^{\circ}$ DUE De MEDa Sa E HIJA DeL EXmo Sor DUE De LERMa FWDADORA De ESTE CONBENTO PATRONA GENERAL DE TODA LA DESCALCES DE NTRA Sa De LA MERSED REDENSION DECAUTIBOS Y SU GRAN DEBOTA Y BIENHECHORA RUEGEN A DIOS POR ELLA MURIO A QUINZE DE AGOSTO AÑO De 1624”.

Si bien los caracteres tipográficos de ambas laudas son similares, la falta de puntuación y ortografías son manifiestamente diferentes, lo que nos lleva a pensar en manos distintas. No obstante ambos sepulcros corresponden a una misma actuación posterior al fallecimiento del Duque en 1629.

Sobre los cenotafios, arquillos y bóveda, se proyecta una recuperada decoración pictórica, de atractiva policromía, con pequeños ángeles alados que conducen a un rompimiento de gloria, en la parte superior, y sendas calaveras sobre los mármoles, en una visión más terrenal y prosaica de la vida.

-Bornos:

"Existe en esta población el Monasterio de San Gerónimo que por su solidez, capacidad y bella construcción debe repararse y conservarse; y en el mismo están los sepulcros siguientes: -El de D. Francisco Henrique de Rivera, Adelantado Mayor de Andalucía, Señor de Tarifa, Alcalá, Cañete y Bornos; descendiente de los reyes de Castilla y de León, ascendiente de los Duques de Alcalá, y fundador de dicho Monasterio. -El de Da Leonor Ponce de León, hija del Gran Duque y Marqués de Cádiz, D. Rodríguez Ponce de León, esposa del Adelantado. -Y el del Licdo. Gonzalo Hernández de Herrera, Corregidor que fue de Vizcaya, Cuenca, Huete, Jaén, Andújar, Talavera, Vélez y Guadalajara; y falleció siendo Presidente del Consejo del Virrey de Nápoles, el Duque de Alcalá." 
Lamentablemente los consejos, dobles, de la Academia no fueron advertidos y el monasterio de Nuestra Señora del Rosario, de la Orden Jerónima, se encuentra hoy abandonado y en estado de ruina. Pese a ello se trata de un establecimiento de notable presencia y justa y merecida fama ${ }^{25} \mathrm{y}^{26}$.

El Libro de la fundación del monasterio, en el Archivo Histórico Nacional -A.H.N.-, nos da ya cuenta de los primeros pasos de la institución y del papel protector del Adelantado Mayor de Andalucía, don Francisco Enríquez de Ribera, y su esposa, doña Leonor Ponce de León. Se trataba de levantar un Monasterio con todas las dependencias, "tal y tan buena como la de San Jerónimo de Sevilla", sin reparar en gastos y para el que el Adelantado librará distintas partidas económicas con la advertencia de que "En la capilla mayor no se enterraría a nadie a excepción del Adelantado y su mujer o a quien él mandare".

De todas las actuaciones y obras posteriores en el establecimiento se dará, así mismo, balance por parte de los frailes en los libros Actas Capitulares, también, en el A.H.N. Si el año 1494 se toma como fecha fundacional, en noviembre de 1505 se celebrará la primera misa. En 1510 se hizo cubrimiento de la bóveda, por canteros, de "yeso y crucería", y exterior de tejas, sustituyendo a otra anterior "enmaderada". Dos años después estaban concluidas las distintas capillas del cuerpo de la iglesia y la del altar mayor. No obstante, hasta 1516 no se dará por acabada la Iglesia. En las Actas Capitulares de 1523 se hace repaso del Monasterio que contaba ya con todas sus dependencias completadas, así como un rico mobiliario y ajuar litúrgico fruto de numerosas donaciones.

Entre tanto, en 1507 muere $D^{a}$ Leonor y dos años más tarde, en 1509, D. Francisco siendo enterrados en la nave del claustro adjunta al muro de la derecha de la iglesia. Será en mayo de 1523 cuando los monjes deciden "se pasasen a la iglesia y se pusiesen en los dos túmulos que están en lo alto de las gradas del altar mayor". Para este traslado se trajo una bula del Papa Julio II y se colocaron «en los dos sepulcros de mármol», que estaban a los dos lados del altar mayor, «en unas cajas de plomo» ${ }^{27}$. Posteriormente, después de 1558 , se labrarán las dos lápidas que dan fe de los entierros (Figuras 8). En el primer epitafio se lee: "Don FRANco ENRIQUEZ DE RIBa. ADELANTADo MAYOR DE LA ANDALUCIA Sr DE TARIFA ALCALA CAÑETE BORNOS-- DESCENDIENTE DE LOS REYES DE CASTILLA Y DE LEON ASCENDIENTE DE LOS EXmos DUQS DE ALCALA-- FUNDADOr DESTE INSIGNE

${ }^{25}$ MATEOS, I., LÓPEZ-YARTO, A. y PRADOS, J.M.: El Arte de la Orden Jerónima. Historia y mecenazgo, p. 141142.

${ }^{26}$ BARRA RODRÍGUEZ, Manuel: Iglesias y Ermitas de Bornos, p.190-275.

${ }^{27}$ Ibídem. 
MONESTERIO_FALLECIO EN VIII DE FEBo AÑO DE M· D· I X’”. En el borde exterior a la leyenda aparecen las iniciales $\mathrm{S} \cdot \mathrm{T} \cdot \mathrm{T} \cdot \mathrm{L}$.

En el segundo: “Da. LEONOr POnCE DE LEON HIJA DEL GRAn DUQe Y MARQs DE CADIZ DON Ro PONCE DE LEON-- MUGER YGUAL EN NOBLEÇA Y PIEDAD DE NUESTRO ADELANTADO-- FALLECIO EN EL MES DE AGOSTO DE M·D $\cdot \mathrm{V} \cdot \mathrm{II}$ $\mathrm{H} \cdot \mathrm{S} \cdot \mathrm{E}-$.

Figuras 8

Lápidas de D. Francisco Enríquez de Ribera, y su esposa, Da Leonor Ponce de León y ubicación actual
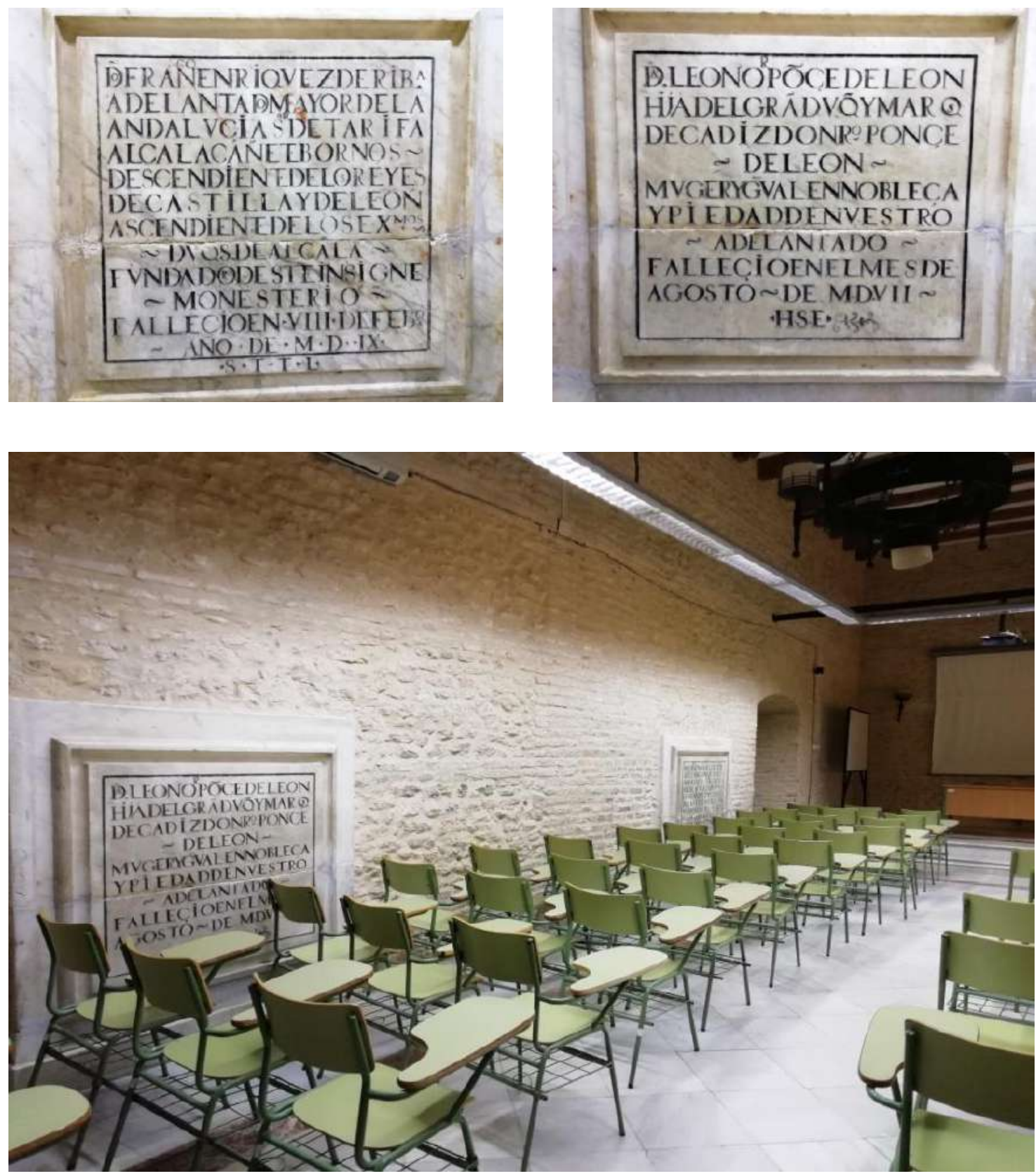
El hecho de hacer constar la ascendencia sobre los Duques de Alcalá, título otorgado por Felipe II en 1558, confirma dicha fecha. Pocos datos más sabemos de los sepulcros, y así se citan en 1601 al referirse al Altar Mayor, “....aparte de los dos sepulcros laterales del fundador y su esposa, que estaban a la derecha e izquierda del mismo"28.

Y, sin más noticias de los sepulcros, a pesar de los inventariados recogidos en las Acta Capitulares por los distintos Priores, llegamos a las exclaustraciones del siglo XIX. La primera, durante la invasión francesa, no afectaría tanto a la fábrica como a las piezas y objetos de arte y joyería. La segunda, en 1820, si bien no podemos concretar los destrozos sí sabemos que los monjes hicieron varias reparaciones a su vuelta en 1822. Durante este cierre, los restos mortales de los fundadores serán trasladados al convento de San Bernardino, también en Bornos, y colocados en el suelo, delante del altar mayor de su iglesia, para, en 1833, regresar, nuevamente, a su emplazamiento de origen en el Monasterio Jerónimo.

La tercera, y definitiva, en 1835, al margen de pérdidas y estragos, conducirá a la clausura y abandono del monasterio. No obstante, los restos y enterramientos permanecerán aún en el templo. En un principio, dichas laudas no se contemplan en los informes e inventarios efectuados por el Gobierno de la provincia, noviembre de 1835, y siguientes, centrándose en otros bienes y obras artísticas tales como cuadros, libros y joyas. Así, y en referencia al Monasterio del Rosario y Altar Mayor no se hace mención de las dos lápidas sepulcrales del fundador y de su esposa que ya estaban en las paredes laterales de capilla mayor, refiriendo sobre estas que solo tenían unas colgaduras de damasco ${ }^{29}$. Posteriormente, agosto de 1840, sucesos de Poblet y Real Orden, sí aparecerán en las preocupaciones de políticos y académicos, como queda recogido.

Será en agosto de 1862 cuando laudas y enterramientos sean llevados a la iglesia del vecino convento de Corpus Christi, quedando las laudas empotradas en los muros de la sacristía.

El convento de Corpus Christi había sido fundado por Per Afán de Ribera y continuado por su hijo Juan de Ribera quien lo consagrará en el año 1.594 bajo el nombre de "Corpus Christi”. De grandes proporciones, dos plantas, constaba de patio porticado, claustro, galería con celdas y una gran huerta. Igualmente la Iglesia, de una nave, y gran amplitud, contaba con importantes capillas y retablos.

Encargado a la Orden de Clarisas Franciscanas será abandonado por las monjas para pasar a la Fundación Medinaceli y en 1973 quedar en estado de ruina. Sacado a subasta, será adquirido por el Ayuntamiento bornense y destinado a fines sociales. En la actualidad, y reformado, funciona como Instituto de Formación Profesional desde 1976.

\footnotetext{
28 Ibídem.

${ }^{29}$ Inventario que se forma, con arreglo a la $5^{\text {a }}$ parte del artículo $3^{\circ}$ de la Instrucción que acompaña a la Real Orden de 25 de julio último, del monasterio, iglesia, ornamentos y alhajas y vasos sagrados que pertenecían al referido monasterio. Archivo Histórico Provincial de Cádiz.
} 
La sacristía pasará a convertirse en la sala de medios audiovisuales del Instituto, restando una última mudanza a las laudas ya que durante las obras de reforma y adaptación a centro de enseñanza pasarán a ocupar el testero opuesto al que se encontraban.

En cuanto al segundo testimonio de Bornos y del propio Convento, el enterramiento “...del Licdo. Gonzalo Hernández de Herrera, Corregidor que fue de Vizcaya, Cuenca, Huete, Jaén, Andújar, Talavera, Vélez y Guadalajara; y falleció siendo Presidente del Consejo del Virrey de Nápoles, el Duque de Alcalá”, no he encontrado referencia alguna acerca del mismo. Se repite la cita del informe pero nada en las Actas Capitulares del Monasterio ni estudios posteriores.

-San Roque.

"En el Cementerio de esta ciudad se ha erigido un pequeño monumento a la memoria de los compañeros del desgraciado Manzanares, que fueron inmolados en dicha ciudad y junto del Campamento" (Figuras 9).

En el cementerio de San Miguel, en San Roque, Campo de Gibraltar, Cádiz, situado en el primer patio de la zona antigua, se encuentra, rodeado de mausoleos y otros enterramientos, un pequeño obelisco, que no por pequeño pierde significación, gloria del liberalismo decimonónico español y que, en el momento histórico de los acontecimientos que relatamos, constituía todo un hito y punto de partida. Se trata de la tumba levantada en honor de los liberales sacrificados en 1831 tanto en la localidad de San Roque como, en la próxima, de Campamento.

Y allí yacen los cuerpos de los veinticuatro revolucionarios que por la libertad dieron su vida ${ }^{30}$. Nueve fusilados en la barriada sanroqueña de Campamento y otros quince junto a las paredes del cementerio de San Miguel, en San Roque. Sepultados en un principio en fosas comunes, tras el retorno de los liberales, y la revolución de 1835, se procedió a la restauración de la memoria histórica. Así, el primero de mayo de 1836 se trasladaron en procesión los restos de los enterrados en el cementerio de San Roque a la parroquia local de Santa María la Coronada, siendo depositados a la derecha del altar mayor. Igual ceremonia se procedió en Campamento, llevándose a hombros los nueve cadáveres hasta el templo sanroqueño, siendo colocados, en este caso, a la izquierda del altar mayor. Tras las exequias y honores militares, sendos féretros fueron trasladados en procesión al cementerio y depositados a los pies del pequeño obelisco. La Milicia Nacional acompañó el desfile, procediéndose a una última descarga. A la ceremonia se unieron autoridades de Gibraltar al encontrarse entre los voluntarios ciudadanos del Peñón.

${ }^{30}$ Para un mejor conocimiento de las circunstancias léase a PÉREZ GIRÓN, Antonio: “Gibraltareños en las filas de los revolucionarios liberales (I y II)", noticiasgibraltar, 17 y 24/03/2018. 


\section{Figuras 9}

\section{Monumento y detalle lápidas conmemorativas}
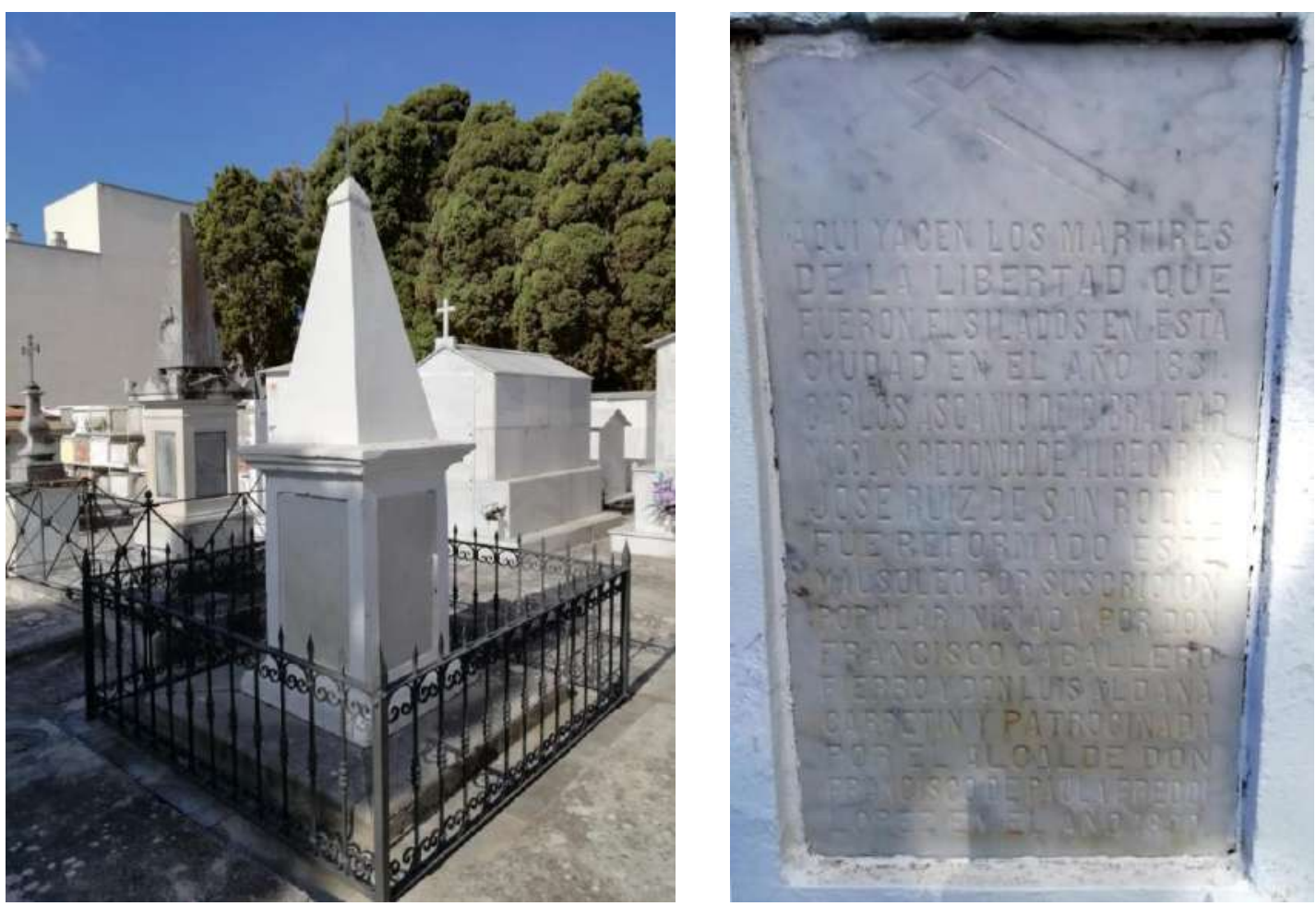

El obelisco, construido en mampostería enfoscada y encalada, presenta un primer cuerpo cuadrado, a manera de pedestal, en cuyos lados se incorporan lapidas de mármol, y un segundo, de forma piramidal, alargado y rematado en una cruz de hierro. Su tamaño, apenas 2,70 metros de altura, y ausencia de ornamento aumenta la simplicidad, sobriedad, del panteón. Una discreta verja cierra el lugar. Un modelo, no obstante, que se aproxima al señalado y recogido, por Soto Caba para estos fines: "Este modelo de obelisco sobre una sucesión de basamentos prismáticos tuvo precedentes anteriores y de nuevo en ambientes liberales, pues así debió ser el monumento provisional que, en la Iglesia del Carmen de Cádiz, levantó Ángel Monasterio para las honras anuales de 1810 por las mismas víctimas del 2 de Mayo" ${ }^{\prime 31}$.

Las placas de mármol verifican la gloria de los héroes: $1^{\text {a }}$. Aqui yacen los mártires de la Libertad que fueron fusilados en esta ciudad en el año 1831. Carlos Ascanio de Gibraltar. Nicolás Redondo de Algeciras. José Ruiz. de San Roque. Fue reformado este mausoleo por suscripción popular iniciada por Don Francisco Caballero Fierro y Don Luis Aldana Carretin y patrocinada por el Alcalde Don francisco de Paula Freddi López en el año 1890. 2a Juan Perez de San Roque. Juan Gómez de Algeciras. Andrés

${ }^{31}$ SOTO CABA, Victoria.: "Renovación y ocaso de un genero. Cenotafios reales y tumbas de héroes en el Madrid del siglo XIX”, Madrid en el contexto de lo Hispánico desde la época de los Descubrimientos, T. II, Madrid, 1994, pp. $1240-1241$. 
Porras de San Roque. Alonso Aguilar de Coín. Cayetano Toledo de San Roque. Placido Condal de Barcelona. Francisco Pérez de Málaga. $3^{a}$ Gaspar Bernal de Alicante. José Caballero de Gibraltar. Francisco Chah de Gibraltar. Francisco José Ramón Franco de Gibraltar. Andrés Caballero de Gibraltar. Pedro Antonio de la Arena de Gibraltar. Juan Ferreiro. 4ª Antonio Rosa de Almachar. Francisco Pérez. de Crevillente. Cayetano Carcamo de Sevilla. Martín Borrel de Barcelona. Francisco Carrasco de Almuñecar. Andrés Ribe de Gibraltar. Antonio Bergara de Alicante.

La mención a una reforma en 1890 en el listado nominal, sin quebranto de mensaje y forma, nos lleva a pensar que las cuatro lápidas se puedan corresponder con la propia reforma más que con la data fundacional.

-Cádiz. Con respecto a la capital y arquitectura funeraria, la Academia

“... concluye diciendo que en Cádiz no existe más sepulcro notable que el grandioso cenotafio de mármol, sito en la Iglesia del Carmen, erigido a la memoria de D. Federico Gravina Capitán General de la Armada muerto de resultas de herida recibida en la batalla naval dado sobre el Cabo Trafalgar; de invención y ejecución del difunto D. Felipe -Cosme en puridad- Velázquez"32 (Figuras 10).

Muchos son los datos que hoy poseemos de D. Federico Gravina y Nápoli y cuyo actual sepulcro en el P. M. I. de San Fernando constituye, sin la menor duda, una joya del arte funerario.

Sabemos que en los primeros días de marzo de 1806, en su casa de Cádiz, se agrava su estado de salud a resultas de las heridas contraídas en la reciente batalla de Trafalgar, falleciendo en la amanecida del 9. En su misma habitación quedó instalada la capilla ardiente y el día 11 se celebraron los funerales en la Iglesia de el Carmen y la misa de «córpore insepulto». El féretro, que iba cubierto de terciopelo negro galoneado de rojo, fue colocado en la iglesia del Carmen sobre un túmulo de cuatro cuerpos levantado en el crucero. "Terminada la función religiosa, el cuerpo fue llevado a la capilla baja del panteón del Carmelo. Allí el cadáver fue pasado a una caja de plomo y sus íntimos amigos, con el deseo de que el cuerpo se conservase intacto, y no pareciéndoles suficiente el embalsamamiento, llenaron la caja de espíritu de vino. Al caer la tarde, en hora próxima al toque de oración, fue conducido el cuerpo a un aposento contiguo a la entonces capilla de San José de Extramuros" 33 .

\footnotetext{
32 El escultor logroñés Cosme Velázquez fue una figura destacadas del arte en Cádiz entre los siglos XVIII y XIX. Fue un artista fecundo que participó en muchas obras realizadas en la ciudad y trabajó como profesor de escultura de la Escuela de Nobles Artes de Cádiz, transmitiendo el estilo academicista que él había adquirido en la Real Academia de Bellas Artes de San Fernando. José Luis Melendreras Gimeno "Cosme Velázquez, director de escultura en la Escuela de Bellas Artes de Cádiz “, Rev. Gades, N 11, 1983, págs. 249-254.

33 BLANCA CARLIER, José Ma: Gravina, su muerte en Cádiz. I, II y III,

http://www.islabahia.com/culturalia/01 historia/gravinasumuerteencadiz.asp. 13/9/2018.
} 
El templo carmelita era obra del alarife José Bolaños, entre los años de 1743 y 1762. Siguiendo el modelo repetido del barroco dieciochesco gaditano, presenta planta de cruz latina, con nave central, de mayor altura, y laterales que acogen toda una serie de capillas y retablos. La bóveda principal es de cañón con cúpula gallonada y pechinas en el crucero. Es en el exterior, donde el templo ofrece toda su singularidad. Con pórtico de mármol, columnado, se remata la parte superior por sendas espadañas de profusa y movida decoración de clara influencia americana, que nos hace pensar en un arte de ida y vuelta.

Pero, hallándose en Madrid su hermano Pedro, miembro de la Nunciatura eclesiástica, vendrá pronto a Cádiz para, igualmente, celebrar nuevos funerales, esta vez por parte de la familia y albaceas, los que se efectuarán en la misma iglesia y 29 del mismo mes.

Con más aparato, Blanca Carlier nos ofrece una detallada descripción del catafalco: "El túmulo, que fue colocado en el centro del crucero, tenía una altura de diecinueve varas $(0,8359 \times 19=16 \mathrm{~ms}$. apx.). Sobre el primer cuerpo del túmulo descansaban cuatro figuras que representaban a la Religión, la Justicia, la Liberalidad y la Fortaleza, como atributos de los sufrimientos padecidos por Gravina, de su recto proceder, su caritativo desprendimiento y su fuerte temple.

El frente principal del segundo cuerpo ostentaba las armas de la Casa de los Gravina. Ocupando los tres frentes restantes había varias pinturas alusivas a sus condecoraciones (gran cruz de Carlos III, militar de Santiago, etc.) y trofeos militares y marineros. Estos dos cuerpos sostenían una cornisa, destacando sobre ella una figura de mujer que descansaba la cabeza sobre su mano derecha en afligido ademán, mientras que con la izquierda sostenía un ancla dorada. Esta figura se hallaba rodeada de libros, cartas náuticas, sextantes, cronómetros y otros instrumentos náuticos y representaba a la Marina. En cada uno de los cuatro ángulos de la cornisa ardían cinco grandes cirios amarillos. El remate de tan suntuoso catafalco estaba constituido por una base imitando jaspes, coronada por una esfera que sustentaba una pequeña pirámide. Desde la cúpula del túmulo pendían sobre él, en forma de pabellón, cuatro colgaduras negras, cuyos extremos se hallaban afianzados en las cornisas de los arcos torales. Sobre los arcos del cuerpo de la iglesia había cuadros alusivos a los empleos del finado capitán general.

Con respecto al esplendor de estos funerales hay que hacer constar que si el aparato funerario fue majestuoso se debió a que la familia Gravina tenía derecho a sepultura real. Este privilegio les había sido concedido en Sicilia por el rey Martino. En la catedral de Catania, 
donde existe la capilla real, se encuentra el panteón de los monarcas, en cuyo frente se hallan colocados juntos los escudos de las armas reales y el de la Casa de los Gravina" ${ }^{34}$. De carácter provisional, este monumento funerario no se parece en nada al existente en el P. M. I.

Pero, continúa Blanca Carlier, durante la guerra de la Independencia, en 1810, Monseñor Gravina regresa a Cádiz, en calidad de nuncio apostólico de Su Santidad. Exhuma los restos de Federico, que se hallaban en el cementerio de San José, trasladándolos, nuevamente, al convento de Carmelitas Descalzos, iglesia donde se habían celebrado los funerales. Quedó enterrado en el muro del costado izquierdo de la puerta del crucero, frente al Sagrario, en un mausoleo de mármoles blancos y negros con adornos de bronce dorado, costeado por él mismo, y leyenda en el frontal que decía así: «A FEDERICO GRAVINA, DE PALERMO, QUE POR EL ESCLARECIDO VALOR Y NOBLEZA DE SU ESTIRPE FUE TENIDO EN GRAN ESTIMA POR LOS REYES CATÓLICOS CARLOS III Y IV; QUE FUE BIEN DISTINGUIDO CON LAS MÁS ALTAS ENCOMIENDAS; QUE SUPO DESEMPEÑAR SABIA Y FELIZMENTE EL CARGO DE EMBAJADOR EN PARÍS EN CIRCUNSTANCIAS BIEN DIFÍCILES; QUE EJERCÍA EL MANDO SUPREMO EN EL EJÉRCITO Y LA ARMADA; QUE DIO SIEMPRE EN TODAS PARTES, EN LA MAR Y EN LA TIERRA FIRME, EN LAS GUERRAS DE ÁFrICA, PORTUGAL, FRANCIA E INGLATERRA, PRUEBAS DE INVICTO VALOR ACREDITADO CON SANGRE Y PROPIO DE UN CAUDILLO ESFORZADÍSIMO; JEFE POR MAR Y TIERRA, EN LA GUERRA MAURITANA, LUSITANA, GÁLICA, BRITANA, SIEMPRE Y EN TODAS PARTES CON INVENCIBLE VALOR, HABIENDO RECIBIDO HERIDAS, Y QUE FINALMENTE, EN LA BATALLA NAVAL CERCA DE TRAFALGAR, FUE MORTALMENTE HERIDO Y MUY LUEGO ARREBATADO A LA VIDA; SU HERMANO PEDRO, ARZOBISPO DE NICEA Y NUNCIO DEL PONTÍFICE EN ESPAÑA, HABIENDO SIDO TRASLADADOS LOS RESTOS DESPUÉS DE CUATRO AÑOS DESDE EL CEMENTERIO PÚBLICO, LE DEDICO AFLIGIDÍSIMO ESTE MONUMENTO. VIVIÓ 49 AÑOS. MURIÓ EN 1806» ${ }^{35}$.

Con este motivo y visita, Monseñor consagró el templo carmelita, como atestigua en la actualidad una lápida situada al lado derecho de la iglesia, junto al altar dedicado a Santa Teresa.

\footnotetext{
34 Ibídem.

35 Ibídem.
} 


\section{Figuras 10}

\section{Boceto (Biblioteca Nacional) y panteón de D. Federico Gravina}
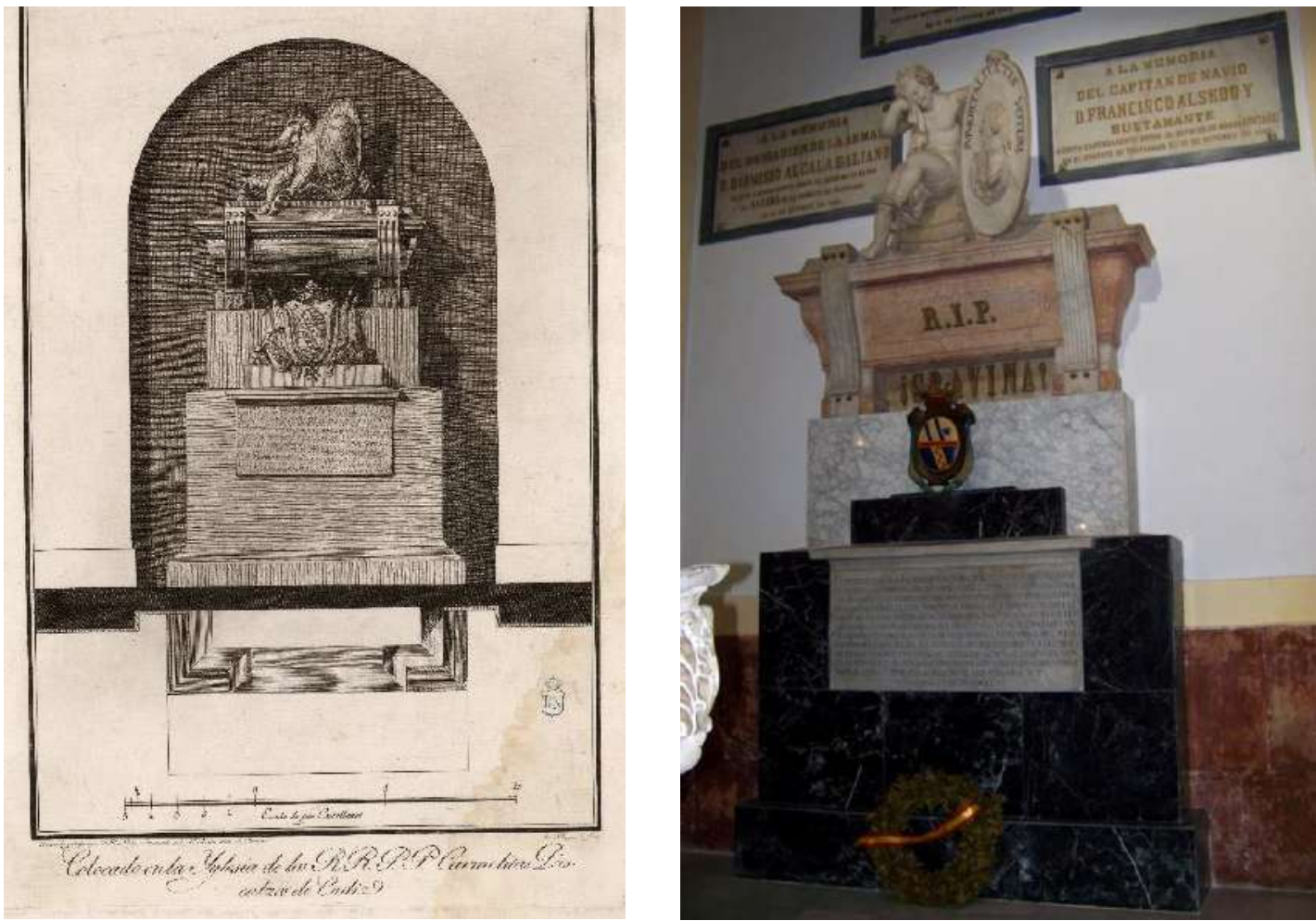

Abierto en el verano de 1854 el P. M. I. de San Fernando, se dispuso el traslado de los restos de Gravina al nuevo emplazamiento. Del mausoleo del Carmen se extrajo el sombrero y el bastón de mando así como las piezas del sepulcro y la lápida que lo cubría, siendo todo trasladado a San Fernando. No obstante, en el Carmen quedaron dos cajas de plomo, una que contenía el cuerpo, con la inscripción en latín: «Huesos de Federico Gravina en espera de la resurrección. Muerto en 9 de marzo de 1806. Enterrado el 11 de marzo de 1806», y otra, más pequeña, que contenía sus entrañas.

En este caso sí nos consta el traslado material del mausoleo, piezas y lápida, así como el academicismo formal de su autor, Cosme Velázquez. El mismo que hoy se encuentra en el P. M. I. y que consta de basamento, formado por tres paralelogramos, de mármoles blancos y negros, uno a manera de zócalo, un segundo que acoge la lápida, ya descrita, y el tercero con el escudo familiar, de viva policromía y emblema, y catafalco, propiamente dicho, con urna y tapa, en mármol rosa y la leyenda “GGRAVINA! R.I.P.”. Como remate, un niño desnudo, acaso un angelote, sentado en un almohadón sobre la tapa, llora al héroe con un pañuelo en su mano derecha y ovalo con el busto y lema "OFRENDA DE INMORTALIDAD”, en la izquierda. Todo ello, también, en mármol blanco y serena contención. 
Pero en 1869, los restos vuelven a tener un nuevo emplazamiento. El gobierno de la Gloriosa, septiembre de 1868, dispone su traslado al, ya citado, Panteón Nacional de Hombres Ilustres, recién inaugurado en el templo de San Francisco el Grande de Madrid. Ahora son exhumadas, también, las dos cajas existentes en el Carmen de Cádiz.

El traslado se efectuará, con todos los honores y asistencia de las máximas autoridades castrenses, en barco hasta La Carraca y por ferrocarril hasta Madrid. Y allí permanecerán hasta abril de 1883 en que, bajo el reinado de Alfonso XII, regresen definitivamente a la Ilustre morada de San Fernando ${ }^{36}$.

Cuando la caja fue abierta, los presentes quedaron asombrados al comprobar que el cuerpo de Gravina se hallaba casi intacto por estar sumergido en alcohol.

No un mal final para tan largo recorrido.

\section{Bibliografía}

AROCA VICENTI, F: El Arte en Jerez: Historia de Jerez de la Frontera, vol. 3., Diputación P. de Cádiz, 1999.

BARRA RODRÍGUEZ, M.: Iglesias y Ermitas de Bornos, Diputación P. de Cádiz, 1995.

CABALLERO OLIVER, J. D.: "Conventos femeninos de clausura en Sanlúcar. Convento de las Descalzas", Revista Sanlúcar de Barrameda, no 27, Ed. Santa Teresa, Sanlúcar de Barrameda, 1991.

CASTELL, J.M.: Las asociaciones religiosas en la España Contemporánea. Un estudio jurídicoadministrativo., 1767-1965, Taurus, 1973.

CRUZ ISIDORO, F.: Alonso de Vandelvira (1544-ca.1626/7). Tratadista y Arquitecto Andalur, Sevilla, Secretariado de Publicaciones de la Universidad de Sevilla, 2001.

FERRATER, E. de, y FERIGLE, P.: Recopilación Estractada, Ordenada y Metódica de las Leyes y Reales Disposiciones promulgadas en los años desde el de 1833 al 1841, incluyendo las de la anterior época constitucional que han sido validadas., Tomo III, Barcelona, 1841.

FERREIRA FERNÁNDEZ, M.: "Nuevas aportaciones sobre el escultor Cosme Velázquez (1755-1837)", Trocadero, no 27 (2015), pp. 123-149.

GARRIDO NEVA, R.: "Una alternativa al mecenazgo ducal, el convento de Santa Teresa de Sanlúcar de Barrameda (Descalzas)”, en F. Cruz Isidoro (coord. y ed.), Sanlúcar Señorial y Atlántica. III y IV Jornadas de Investigación del Patrimonio Histórico-Artístico 2013-2014, Sanlúcar de Barrameda, Ayuntamiento de Sanlúcar de Barrameda. 
LÓPEZ GARRIDO, J.L., MARTÍNEZ MONTIEL, L.F., y RAMÍREZ MALO, F.: Guía bistórico-artística de San Fernando, F.M.C., Ayuntamiento de San Fernando, 1989.

NAVASCUÉS PALACIO, P.: “Los sepulcros reales de Poblet”, Descubrir el Arte (19), 2000.

MATEOS, I.; LÓPEZ-YARTO, A. y PRADOS, J.M.: El Arte de la Orden Jerónima. Historia y mecenargo, Encuentro, 1999.

MORALES, A. J.: "Alonso de Vandelvira y Juan de Oviedo en la iglesia de la Merced de Sanlúcar de Barrameda", Boletín del Seminario de Estudios de Arte y Arqueología, Valladolid, 1981.

OSLÉ MUÑOZ, J.: El convento de las Descalras, Ed. Asociación Sanluqueña de Encuentros con la Historia y el Arte (ASEHA), Sanlúcar de Barrameda, 1996.

SOTO CABA, V:: "Renovación y ocaso de un genero. Cenotafios reales y tumbas de héroes en el Madrid del siglo XIX", Madrid en el contexto de lo Hispánico desde la época de los Descubrimientos, T. II, Madrid, 1994.

VARGAS Y PONCE, J. de: Vida de D. Juan Josef Navarro, primer Marqués de la Victoria, Madrid (Imprenta REAL), [s.n.], 1808.

VELÁZQUEZ-GAZTELU, J. P.: Fundaciones de todas las iglesias, conventos y ermitas de la Muy Noble y Muy Leal Ciudad de Sanlúcar de Barrameda., Año de 1758 (Manuscrito en paradero desconocido, trascripción manuscrita de Manuel López de Piedra (¿año?). Estudio preliminar y trascripción de Manuel Romero Tallafigo; dibujos de Cristóbal Mancha Liñán., Asociación Sanluqueña de Encuentros con la Historia y el Arte (ASEHA), Sanlúcar de Barrameda (Cádiz), 1995.

----- Catalogo de todas las personas ilustres y notables de esta ciudad de Sanlúcar de Barrameda. Desde la mayor antigüedad que se ha podido encontrar en lo escrito, hasta este año de 1760. Estudio preliminar, transcripción y edición del manuscrito por Fernando Cruz Isidoro; dibujos de Cristóbal Mancha Liñán. Asociación Sanluqueña de Encuentros con la Historia y el Arte (ASEHA), Sanlúcar de Barrameda (Cádiz), 1996. 